\title{
SOBRE LOS COMPUESTOS NOMINALES LATINOS CON PREFIJO DE VALOR INTENSIVO
}

It is a common opinion among latin grammarians that praepositions often have a uis intentiua. Modern grammarians, however, only admit this value in those composita with per- and prae-. The author of this paper maintains that according to ancient latin theories, besides per and prae there were other praepositions with intensive value in composition.

An analogous phaenomenon can be traced in Greek and other Indoeuropean languages. He also tries to make clear the uniqueness of these forms.

Los problemas que plantean los compuestos nominales (y adverbiales) latinos con las características indicadas en el epigrafe constituyen uno de los puntos más complejos y oscuros de la morfología latina (y en general de la morfologia indoeuropea). La prueba es que hasta ahora apenas si se ha podido explicar ni una sola de las particularidades tan extrañas que presentan los hasta ahora reconocidos como tales; es decir, los compuestos con los prefijos per- y prae-. Por ejemplo, el que sean tan escasos los que llegaron a cristalizar en formas estables y permanentes y de uso general en la lengua; y el que cuando alcanzaron su máximo desarrollo fuese en época relativamente tardía, los en per- en los escritos de Cicerón y los con prae- en el imperio; y el que en esa misma época los con per-aparezcan construidos a veces en tmesis. Detalles todos que parecen indicar que en aquel momento la formación todavía no había llegado a realizarse plenamente. Por lo demás, se ve que a partir de Cicerón hay un descenso rápido y claro en el número de formas nuevas del tipo con mucho más frecuente de los compuestos con per-. La prueba es que las formas nuevas atestiguadas en los cinco siglos siguientes (en total aproximadamente $\mathrm{I}_{4} 8$ ) apenas sobrepasan dos docenas las formas atestiguadas en Cicerón (unas 128). Señal inequívoca de que la formación entró en una fase clara de decadencia. $\mathrm{Y}$ el caso es que a su vez esas formas tardías siguen presentando el mismo carácter de precariedad e inestabilidad que las más antiguas. Pues sólo una infima minoría de ellas (es decir, aproximadamente el 
Io por 100), aparecen documentadas en más que en uno o dos ejemplos ${ }^{1}$. Lo cual produce la impresión de que se tratase de un procedimiento frustrado, de algo que hubiese chocado con tendencias íntimas más fuertes, que en gran parte impidieron su desarrollo. Y lo más sorprendente de todo es que por otra parte formaciones del mismo tipo, es decir, con el prefijo al parecer correspondiente al latino per- y con sentido igualmente intensivo se da en un grupo amplio de lenguas ide. Por

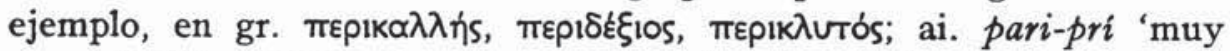
amado', lit. per̃didis 'muy grande', ant. esl. préblagu 'muy bueno', ant. irl. er-chomil 'persimilis'. Lo cual parece indicar que el procedimiento tuvo que proceder del ide. Cosa que naturalmente no se ve cómo pueda conciliarse con esas otras circunstancias, a las que las formas latinas aparecen ligadas.

Son estas las aporías con que los considerados por excelencia compuestos intensivos nos enfrentan. Aporias ante las que los gramáticos no han dado, ni siquiera han tratado de dar una contestación. Pues el punto principal que ha suscitado algunas discusiones ha sido el referente a si la formación con per-procedió o no del ide., y el anejo a este de si el per-latino fue el mismo elemento que el prefijo externamente igual de las otras lenguas. Punto sobre el que tampoco han llegado a ponerse de acuerdo los autores. Pues, aunque hoy día ha ido imponiéndose la opinión de que las formaciones de las diversas lenguas tuvieron la misma naturaleza y procedieron del ide., todavía Leumann, $H$. Gr.6. p. 40I, reafirmándose en una idea antigua suya (Festschr. Wackernagel, p. 339, recogida en $H$. Gr.5, p. 253), sigue sosteniendo que el lat. per-continuó, no la preposición per de las otras lenguas ide., sino una partícula enclítica -per. $\mathrm{Y}$ prescindiendo del juicio sobre esta hipótesis, que estudiaré luego, es claro que hay fuertes razones para dudar de que los hechos latinos tuviesen una gestación tan sencilla como se supone.

Por lo demás, los problemas de los compuestos intensivos latinos no se agotan con esto. Pues los gramáticos latinos dicen que ese valor intensivo (uis intentiua) lo tuvieron, además de per y prae otras preposiciones. Por ejemplo, la ad-, cf. A. Gel. VII 7, 7: nam et adpotus cum dicimus, et adprimus et adprime, intentio his in uerbis demostratur; y VII 7, 8: adprobus... quod significat ualde probus. Y la ex, $\bar{e}$, de la que a propósito de egelido flumine (Virg., Aen. VIII 6ro) dice Servio: id est

1 Tomo los datos de J. André, Les adjectifs et adverbes de valeur intensive en per-et prae-, REL 29, I951, p. 121 ss. 
nimium gelidum; et est una pars orationis ut eduramque pirum (Georg. IV 4I5), id est ualde duram. Y la in-, sobre la que fue una doctrina constante y general en la tradición gramatical antigua que, entre otros varios, tuvo un valor intensivo. Así el Auctor de differentiis (GLK VII, p. 528, 18): "in» aut "intus» significat, aut "nimis», aut "ualde», et interdum pro "non" ponitur. Y Diomedes (GLK I, p. 4II, I5): "In" praepositio significat modo quod est "ualde», et uim uerbi cui adponitur auget (y de acuerdo con él Dositeo, GLK VII, p. 4I4, I6). Y Carisio, GLK I, p. 236, 6: "In" praepositio derogativa est... nonnumquam adjectiva (= intentiua) ${ }^{1}$. Y Probo, GLK IV, p. 150, 5: "In" et "de" praepositiones duplicem significationem habere reperiuntur; modo enim augent... nunc minuunt. $\mathbf{Y}$ Prisciano, Institut. I4, 50 (GLK III, p. 53, 21): in compositione quoque (sc. in) diuersas habet significationes quam in appositione; modo enim priuatiua est, ut «indoctus»... modo intentiua, ut "in primo, incuruo, irrideo"... Y por supuesto prae, Carisio, GLK I, p. 306, 3: Item prae diuersas habet significationes; accipitur enim pro ualde, ut cum dicimus praedurum uolnus... Doctrina que había de pasar a las gramáticas de la Edad Media; cf. Corpus Grammaticorum Medii Aeui, ed. J. Wrabel, Breslau, I887.

Y tradición que por cierto está plenamente confirmada por los textos. Pues en latín, aparte de los con per- y prae-, hay una serie de compuestos nominales con esas preposiciones a que se refieren los gramáticos, y con otras como $c u m, o b$, de cuyo valor, en principio intensivo, parece que no se puede dudar. Por ejemplo, y prescindiendo de las palabras atestiguadas sólo en los lexicógrafos o en autores tardíos, con ad-: adaequē, adpōtus, adprobē, adprimus, adsimilis (desde Plauto), aduncus (desde Ter.), adfabrē (desde Cic.). Y con con-: concauos (desde Enn. y Cat.), condensus (desde Lucr.), condignus, compar ${ }^{2}$,

1 Aunque como ejemplo del valor intensivo Carisio aduce impotem, quod est ualde potens, donde el sentido de 'impetuoso, violento, furioso' no fue más que un desarrollo del de 'desapoderado, sin dominio de si', de la partícula privativa in.

2 A compar, atestiguado en Plaut., quiere considerarlo Stolz-Leumann, H. $G r_{.6}$, p. 400 , un regresivo de comparäre (atestiguado en Ter.) fundándose en el femenino compara de Carm. Epigr. 218, 3. Pero compara es una forma aislada, y desde luego muy posterior a compar y a comparāre. Es, pues, evidente que hay que partir de compar, forma a su vez anterior a comparäre 'comparar' y, por lo tanto, difícil de explicar como regresivo. $\mathrm{Y}$ por lo demás yo tampoco creo que pueda reducirse al tipo conseruos, condiscipulus, etc., como indica Bader, La formation des composés nominaux, 379. Ya que este tipo sólo puede darse con tema nominal en el segundo miembro del compuesto. No parece, pues, que pueda tomársele más que por un intensivo con el sentido de "completamente igual (así Stolz, H. Gr., 1894, p. 397). 
complūres ${ }^{1}$, consimilis, consūcidus (desde Plaut.), contristis (desde Ter.), contumax (desde Rhet. ad Herenn.). Y con $\bar{e}, e x$-: $\bar{e} d \bar{u} r u s$ (desde Virg.), efferus (desde Acc.), effētus (desde Lucr. y Cicer.), ègelidus (desde Catulo), èualidus (desde Cic.), èuānidus (desde Ovid.), èuidens (desde Cic.), exalbidus (desde Plin.), exōsus (desde Virg.), expallidus (desde Suet.), expauidus (desde Livio). Y con in-: illustris, incānus, inclitus (desde P1.), incupidus (desde Afran.), incuruos (desde Tert.) e incuruiceruicus (desde Pacuvio), infensus (desde P1.), insignis (desde Cat.). Y con ob-: obaerätus (desde Varr.), obēsus (desde Liv.), oblongus (desde P1.), obmeritus (CIL VIII, pp. 3892, 5 y 4079, 8) ${ }^{2}$, obniger (desde Plin.), oblüridus (Amm.), obscaeuos (desde Non.) ${ }^{3}$, obscēnus (desde P1.) ${ }^{4}$, obuncus, obustus (desde Virg.).

Ejemplos doblemente significativos, porque a su vez en griego, según veremos, existen aún más desarrolladas que en latín formaciones del mismo tipo; es decir, compuestos con prefijos, a veces con prefijos correspondientes a los latinos y con valor intensivo. A pesar de lo cual en latín no se suele admitir que hubiese habido más compuestos intensivos que los con per- y prae-. Y, aun a éstos, suele considerárselos, no como formaciones autónomas, sino como un apéndice de los compuestos verbales, de los que nunca se habrian desligado por completo. Lo cual representa un retroceso respecto al punto al que ya había llegado Stolz,

1 A complūres quieren considerarlo Leumann, Sprache I, 1949, p. 204 y Ba-

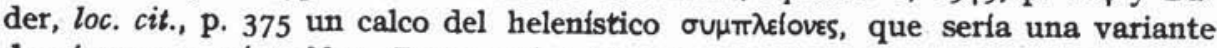

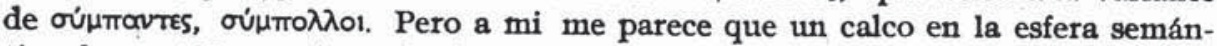
tica de complüres seria un fenómeno sumamente inverosímil. Hay, pues, que pensar que complūres no pudo ser más que un intènsivo sobre plūres, del mismo tipo

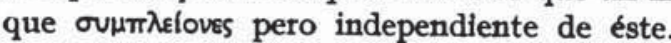

2 A éste le dan algunos, como el Thesaurus y Bader, como un posible hipostático sobre $o b$ merita. Pero en los dos pasajes en que aparece atestiguado va asociado a otro superlativo optumae y rarissimae, sin duda errata en vez de carissumae. Todo, pues, indica que debió tener un sentido superlativo, difícil de explicar en un hipostático y completamente natural en un compuesto con $o b$.

- Obscaeuos está atestiguado en Nonio I, 212, con el sentido de 'muy cruel' - 'funesto' (sc. omen). Desde luego atestiguado como explicación de un obscaeuãuit (Asin. 266) y un obscaeuāui (Stichus 46r), que a mi juicio no son más que unas formas fantasma; es decir, unas falsas lecturas en vez de obseruärit y obseruāui (cf. Actas del 5." Congreso Español de Estudios Clásicos, pp. 71-72). Pero en todo caso entiendo que sobre su existencia no caben dudas.

- Incluyo a obscaenus/obscenus en este grupo, porque, a mi juicio, no puede ser más que un compuesto de obs- más caenus, sobre la raíz de caenus 'sucio, fangoso, repugnante' (cf., igualmente, Actas del 5." Congreso Español de Estudios Cldsicos, p. 69 ss.) 
$H$. Gr., 1894, p. 397 , quien ya habia reconocido el carácter intensivo de algunas de estas formas. Actitud por lo mismo extraña, pero que hasta cierto punto tiene su razón de ser, al menos en los compuestos distintos de los con per- y prae-. En primer lugar porque esos compuestos con prefijos distintos del per- y prae- constituyen grupos reducidos, grupos que no parece que ofrezcan base para hablar de una categoria aparte. $A$ lo cual se añade otra circunstancia perturbadora. $Y$ es que frente a lo que ocurre en los con per-y prae-, que presentan siempre un sentido intensivo o superlativo claro, en los otros compuestos con esos prefijos su carácter intensivo está muchas veces atenuado $\mathrm{u}$ oscurecido. Por ejemplo, es muy difícil determinar lo que aduncus o concauos o èdūrus, u obdūrus, oblongus, o exabildus, etc., añadieron de más al sentido de los simples respectivos. Y esa diferencia fue ya imperceptible a los mismos gramáticos latinos. Por ejemplo, en relación con in- ellos nos dicen que, además de intensivo, algunas veces era un prefijo expletivo, que no añadía nada al valor del simple. Así Diomedes, GLK I, p. 4II, 3I (y de acuerdo con él Dositeo, p. 4I5,3) dice: interdum et pro particula supervacua (sc. ponitur): nosco crines incanaque menta. Y CGL V, p. 209, 33: in plerumque quod inuenerit seruat.

$\mathrm{Y}$ de acuerdo con esto se ve que un mismo compuesto (de los con prefijo distinto del per- y prae-) se ve que aparece revestido con matices diversos, según los autores y las épocas. Asf égelidus, que en unos autores significa 'tibio' y en otros 'muy frío'. Y lo mismo effēta, que de ordinario tiene el sentido de 'agotada o exhausta por los partos', $\mathrm{y}$ otras veces equivale al simple fèta 'parida' o 'que ha dado a luz', y otras a 'embarazada'. Y oblongus, atestiguado en Plauto con el sentido de 'muy largo' (oblongis malis, Mil. 643), que con el tiempo terminó especificándose en el de 'algo largo, algo más largo que ancho'. $\mathrm{Y}$ de ahí las vacilaciones que se notan en los mismos gramáticos sobre el sentido de algunos compuestos particulares. Por ejemplo, el incāna de Virgil., Georg. III 33I (referido a los Cinifios): barbas incanaque menta... tondent hirci; Servio lo comenta: incana autem dixit nimium cana. En cambio al incāna del mismo Virgil., Aen. VI 809 (referido a Numa), Diom., loc. cit., le da como compuesto con in particula superuacua. $\mathrm{Y}$ que desde luego tuvo a veces un sentido atenuado como de "algo cano, entrecano, mezclado de blanco y rubio" parece evidente. Así P1., Rudens 126: Ecquem tu hic hominem crispum, incanum uideris? Y Suet., Domit. 20: caput uarietate capilli subnitidum et incanum perfusam niuem mulso dixit. Y Colum. VIII 2, 9: barbae (sc. gallinarum) ex rutilo albicantes, quae uelut incanae barbae dependent. Lo cual explica que los glosarios le atribuyan el sentido de 'entrecano', GGL II, p. 435, 24: 


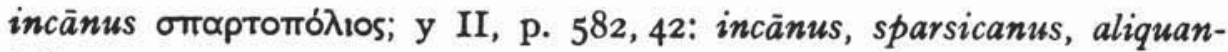
tulum canus.

Ahora bien, como veremos a continuación, estos hechos significan muy poco sobre el verdadero carácter de los compuestos. Pero los autores modernos, que no han visto la causa de tales fluctuaciones, las han tomado como una prueba de que en latín, dentro de las formaciones con esas preposiciones, no hubo compuestos intensivos fuera de algunos tardíos y aislados con in- y ex-. Por lo demás, donde se ve que realmente abundan más las formaciones con valor intensivo claro es en los compuestos verbales y por supuesto en sus participios (en los compuestos verbales con los más 'iversos prefijos). Así es que la tendencia general entre los autores modernos ha sido poner en relación los compuestos nominales, tanto los más claramente intensivos con per-y prae-, como los más atenuados, con los derivados claramente intensivos con per- y prae-, con los derivados de compuestos verbales; es decir, considerarlos analogías de los compuestos nominales de origen verbal, o regresivos (postverbales). Idea, sin duda, en el fondo, según veremos, no mal orientada.

Pero en los compuestos con per-y prae- se ve que una serie numerosísima de ellos se construyeron directamente sobre temas nominales sin relación ninguna con temas verbales: peramplus, perbene, perblandus, perbonus, perbreuis, pergrandis, permagnus, permultum, perpaucus, etc. Lo cual prueba que, cualquiera que hubiese sido su origen, con el tiempo se desprendieron de él, y se constituyeron como categoría independiente, capaz de dar directamente compuestos sobre cualquier clase de temas nominales. $\mathrm{Y}$ naturalmente que lo que ocurrió en los con per- y praepudo producirse lo mismo en los compuestos con otras preposiciones. De modo que en teoria no hay razón ninguna para pensar que los compuestos intensivos con prefijos como $a d$-, con-, ex-, in-, ob- tuvieron que estar necesaria y directamente relacionados con compuestos verbales. $\mathrm{Y}$ que efectivamente en número mayor o menor, tales compuestos, no sólo en los siglos tardíos del imperio, sino ya en la época más antigua existieron, parece indiscutible. La prueba son los ejemplos que he citado más arriba. Para el caso importa poco que la mayoría de ellos hoy se consideren derivados de compuestos verbales o regresivos; pues, como veremos a continuación, esa interpretación no resiste a un análisis detenido. $\mathrm{Y}$ tampoco importan nada las dudas y oscuridades que sobre la naturaleza de algunos de ellos existen. El caso que sin duda presenta un aspecto verdaderamente ambiguo es égelidus.

Pues en el primer pasaje en que aparece atestiguado (Catulo $4, \mathrm{I}$ ) no puede tener más sentido que el de 'tibio': iam uer egelidos refert te- 
pores. Sentido que se encuentra documentado luego en Ovid., Am. II II: et egelidum Boream-egelidumque Notum; y en Colum. X 282: nunc uer egelidum, nunc est mollisimus annus, y en algunos otros autores. Pero el caso es que ese egelidus está atestiguado en una época un poco posterior, pero muy cercana a Catulo, con el sentido opuesto de 'muy frío, helado'. Por ejemplo, Manil. V, I3I (sobre el Polo Norte): (Capella) tollitur... egelido stellata Polo; y Virg., Aen. VIII 6ro: ut procul egelido secretum flumine uidit (sc. natum) (pasaje que Serv. ad locum comenta: id est nimium gelido); Auson. 28I, I: egelido mouet arma Seuerus ab Histro; y 39I, 4: super egelidae stagnantis terga. Mosellae. Dos sentidos, como se ve, difíciles de conciliar, y de los que desde luego hasta ahora no ha podido darse razón. La prueba es que Ernout-Meillet no le toma en consideración; como tampoco le habían tomado Walde, $W b_{2}$, ni Walde-Pokorny. Y Walde-Hofmann lo único que indica es que ègelidus, 1o mismo que, según él, el exalbidus de Plin. debe implicar la idea de 'pérdida del calor'. Lo cual parece presuponer que a su juicio el exen él tuvo el sentido local de "separación", y que originariamente ègelidus significó 'desprovisto de frío, tibio'. Aunque expresamente tampoco llega a afirmarlo, ni indica dentro de qué tipo morfológico le incluye. El que dio algunas precisiones más sobre el caso fue Stolz-Leumann, $H . G r_{.5}$, p. 254, quien le consideró un compuesto de $e x$ con un sentido privativo (derivado de su sentido local de 'fuera de') más gelido de gelu. Un compuesto al que Stolz-Leumann incluyó en el grupo de los llamados 'exocéntricos' o 'posesivos'; pero que sin duda en el caso de que descansase en el $e x$ - privativo no pudo pertenecer más que al grupo de los hipostáticos. $\mathrm{Y}$ un compuesto que en todo caso, tanto en un grupo como en otro, constituiría una anomalía clara y excepcional. Pues el exalbidus de Plin. hay que explicarle como un sencillo compuesto intensivo de ex más albidus con sentido atenuado. Por lo demás, dentro de esa hipótesis es imposible explicar, y, desde luego, ni stolzLeumann ni nadie ha explicado cómo del sentido de 'tibio' podria haberse pasado al contrario de 'muy frío'. Y de ahí que en $\mathrm{H}$. $G r_{\cdot 8}$, p. 400 se limita a incluirle en un grupo de compuestos que, según dice, fueron muchas veces regresivos: expauidus, expallidus, èuänidus. Opinión, como se ve, completamente distinta de la anterior, y por lo demás difícil de comprender, pues no se ve de qué verbo podría ser regresivo ègelidus. Aparte de que como indicaré más adelante, yo tampoco creo que expallidus y èuãnidus puedan ser considerados regresivos.

$\mathrm{Y}$ aparte de que, como digo, dentro de esa tripótesis es imposible explicar y Leumann no explica cómo del sentido de 'tibio' podrfa haberse pasado al de 'muy frio'. 
El que en cambio se ajusta a un tipo morfológico normal es un ègelidus 'muy frío' con el ex intensivo de otras formas más el simple gelidus. La aparente dificultad de esta interpretación radica en que a primera vista parece a su vez imposible el paso inverso del sentido de 'muy frío' al de 'tibio'. Pero lo cierto es que un paso del sentido de 'muy frío' al de 'algo frío' o 'fresco' está de completo acuerdo con el fenómeno de la usura semántica a que están expuestas las expresiones intensivas. $Y$ por otra parte no cabe duda que a su vez la diferencia entre 'algo frío' o 'fresco' y 'algo caliente' era a su vez muy pequeña y hacía fácil la confusión entre ellas. La prueba es que tepor, que por naturaleza y de ordinario significó 'calor suave', en Tác., Hist. III 32, y Diál. 21 está usado con el sentido de 'frescura'. Por lo demás no hay que olvidar que el valor eminentemente privativo del ex hacia doblemente natural la interpretación de ègelidus por 'no frío'. Y por lo demás vemos que los gramáticos latinos reconocieron expresamente en ègelidus un valor intensivo; cf. Serv. ad Virg., Aen. VIII 6ro y Diomedes, loc cit. Luego debemos concluir con el Thesaurus que ègelidus no pudo ser más que eso: un compuesto intensivo con ex más gelidus, de donde con la debilitación semántica de las expresiones intensivas 'algo frío, fresco' y luego 'tibio'. Sentidos ambos que convivieron a lo largo del tiempo en los diversos autores. Desde luego que esto presupone una debilitación semántica de las expresiones intensivas. Pero éste es un fenómeno corriente y por lo demás tiene una causa muy clara. Es que el lenguaje, por una ley inmanente y connatural a su esencia, no es sólo, como pudiera parecer a un moderno el instrumento del pensamiento lógico, sino que nació sobre todo como expresión de emociones, sentimientos e impulsos volitivos. Carácter que del todo no ha perdido ni incluso en nuestra época, después de miles de años de desarrollo del pensamiento racional. Aunque, desde luego, esto es menos perceptible cuanto mayor es el grado de cultura del hablante. Pero en las masas más incultas y espontáneas, y en proporción directa a su grado de cultura, se ve que la lengua está siempre penetrada de afectividad; que toda comunicación del pensamiento va envuelta siempre en una atmósfera afectiva o sentimental; que el lenguaje en suma no es sólo expresión de juicios, sino además de estados de ánimo. Lo cual suele llevar consigo cierta tendencia a la expresividad, en su deseo de producir el mayor efecto en el interlocutor; cierta tendencia a dar a su comunicación una expresión enfática más fuerte de lo que en realidad la corresponde; es decir, que tiende a exagerar. Este abuso de la expresividad, en mayor o menor medida, según el carácter de cada individuo, es corriente en la lengua espontánea de la conversación, aun entre las personas cultas. 
Recuérdense hipérboles, de uso tan generalizado entre nosotros, como 'nos dejó helados, nos dejó de una pieza, vengo muerto de hambre, de sed, de frío, de cansancio, de aburrimiento; a cada paso nos engaña, nos tiene locos con sus historias, se lo ha dicho a todo el mundo'. Y de ahí también la aplicación tan frecuente de epítetos como 'formidable, fenomenal, fantástico, estupendo, maravilloso, horrible, horroroso, alucinante', etc., a hechos triviales de la vida diaria.

Lo cual suele tener por consecuencia un desgaste semántico a que en todas las lenguas están sometidas las expresiones intensivas ${ }^{1}$. Un desgaste que suele llevar a una recreación incesante de nuevas formas intensivas para sustituir a las desgastadas, y que suele traducirse en fenómenos diversos. Entre otros, por ejemplo, los compuestos pleonásticos o pletóricos, es decir, las formas de por sí intensivas o atenuantes, reforzadas con un segundo morfema de la intensidad o de la atenuación. Por ejemplo, los diminutivos como subturpiculus, subcrassulus, subargu-

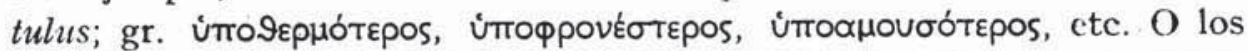
superlativos como perdulcissimus, permaximus, perminimus, perplūrimus, perpessimus, etc.; y los comparativos o superlativos sobre temas

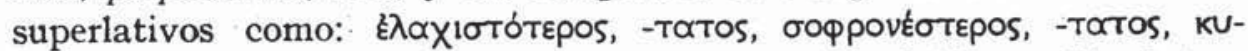

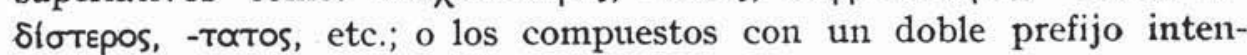
sivo: perillustris, percontumax, perinsignis, perexoptäbilis, etc. Es decir, que pasos del sentido intensivo al atenuado se están produciendo en todas las lenguas incesantemente. Es en este aspecto significativo que los comparativos del griego y del latín, que de suyo tuvieron un valor elativo o ponderativo respecto a un segundo término de la comparación, cuando falta ese segundo término se convierten en formas de la atenuacoón: Senectus est natura loquacior; Themistocles liberius uinebat; " $\mathrm{Hv}$

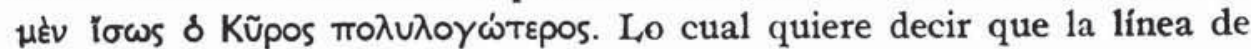
separación entre las expresiones intensivas y las atenuadas o neutras es muy imprecisa e inestable. Tan imprecisa que en todas las lenguas se está produciendo constantemente el paso de las primeras a las segundas.

Lo curioso es que el paso inverso (es decir, el paso a intensivas de las expresiones atenuadas) es muy raro, y en concreto en latín es dudoso que llegase a darse. $\mathrm{Y}$ por otra parte la cosa es que tampoco es fácil comprender cómo, si no fue a través de ese proceso de degradación semántica, tan corriente en las expresiones intensivas, podria haberse

\footnotetext{
1 Fsta tendencia de la lengua a las expresiones reforzadas y su consiguiente desgaste semántico la reconoce ya Szantyr, Lat. Synt.8, p. 297, a propósito de los verbos, pero hay que suponerla igualmente en los nombres.
} 
llegado a esos aparentes expletivos; es decir, a compuestos con prefijos sin valor especial, ni local, ni de ninguna clase. Pues el uso de cualquier morfema está siempre condicionado por el deseo de cubrir alguna función sintáctica o semántica. $\mathrm{Y}$ naturalmente no se comprende que unos elementos con un valor tan concreto y relevante como las preposiciones, pudiesen haberse usado como partículas sin sentido ni razón ninguna. Pues no vamos a pensar que ese uso pudiese haber estado determinado por el simple deseo de aumentar el volumen fonético del simple o por razones rítmicas. Es decir, que la idea de particula superuacua, inventada ingenuamente por los antiguos, es en sí absurda, pues repugna a lo que por esencia son los morfemas. Frente a esto tenemos que la doctrina gramatical vio en tales compuestos un refuerzo del sentido del simple. Luego debemos pensar que todos los compuestos (nominales o verbales) con preposición, en los que no es perceptible el valor local típico de las preposiciones, fueron por naturaleza intensivos, y que sus diversas acepciones y matices derivaron de ese su carácter fundamental.

Lo que tampoco resulta fácil comprender a primera vista es en virtud de qué mecanismo en los compuestos nominales el valor local de las preposiciones se habria convertido en un matiz intensivo. Donde parece que el fenómeno tuvo que producirse de manera más natural es en los compuestos verbales, debido al carácter de adverbios que las preposiciones tuvieron en principio. $\mathrm{Y}$ en general parece que es esa la idea que subyace en las concepciones actuales de los considerados compuestos intensivos, los con per- y prae-. Idea completamente lógica, y que se encuentra apoyada en el hecho de que en los compuestos verbales destaca con mucho mayor relieve y frecuencia, en latín como en todas las lenguas, por ejemplo el griego, el valor intensivo. Pero lo cierto es que esa intuición ha estado enturbiada en los gramáticos modernos por otras varias razones. Una es que por las causas citadas no han visto el carácter intensivo de los compuestos nominales con prefijos distintos del per-y prae-. Y otra porque aun admitiendo vagamente que también los prefijos distintos de per- y prae- dieron compuestos verbales intensivos, no han advertido, ni apenas estudiado, el alcance que el fenómeno tuvo. Aparte de que los gramáticos modernos tampoco han valorado exactamente el salto que suponen compuestos como praeclārus, praedulcis, praelargus, o como pergrandis, permagnus, permultus, perpaucus, etc., respecto a los como praecellens, praeèminens, praedoctus, o como perculsus, perdoctus, perfectus, perterritus, etc. Como a su vez tampoco han establecido con seguridad la naturaleza exacta de los regresivos o postverbales. Ellos lo que han visto es que una multitud de compuestos nominales cọ toda clase de preposiciones, derivaron, 
como es verdad, de compuestos verbales. $\mathrm{Y}$ ante esto, a cualquier compuesto nominal con prefijo, cuyo tema hubiese dado origen a formas verbales, se ha tendido a vincularle y a ponerle en dependencia del verbo respectivo; sin tener en cuenta ni el orden cronológico entre el considerado término primario y secundario, ni en si la supuesta relación puede justificarse morfológicamente. $\mathrm{Y}$ en definitiva han solido explicar tanto a los compuestos arriba citados, como a otros de época posterior o de los glosarios, con las mismas preposiciones ad-, con-, ex-, in-, ob-, o como derivados de compuestos verbales, o como regresivos suyos. Una tendencia surgida muy pronto en la Gramática Histórica y de la que ya Stolz, $H$. Gr., r894, hizo un uso abusivo, y que en latín quedó definitivamente consagrada con la tesis doctoral de $\mathrm{F}$. Brender, Die Rücklaeufige Ableitung im Lateinischen, Basilea, 1920. Es decir, en resumen, que en latín no habría ningún compuesto formado directamente sobre temas nominales e independientemente de los compuestos verbales (a pesar de los innumerables de esta clase que hay en los compuestos con per-, prae- y sub-).

Pero claro está que esa interpretación falla en todos los casos arriba citados y en otros muchos similares de época posterior. Pues el hecho de que el tema nominal, segundo miembro del compuesto, descanse en una raíz o tema verbal, no basta para dar al compuesto como verbal o como regresivo verbal. Por lo menos a mi juicio es en absoluto inadmisible considerar verbales a compuestos nominales con un adjetivo verbal o participio como segundo miembro, cuando no existe el correspondiente verbal compuesto; o cuando si existe, está atestiguado en época posterior al compuesto nominal, o con sentido distinto que este. Es decir, que a mi juicio es imposible considerar verbales a compuestos como concauos, condignus, o como èdürus, èuidens, exaptus, exōsus, o como inclitus, o como obaerātus, obēsus, obmeritus, obustus, o como perösus, pertaesus, pertinax, praeditus, praepotens. Para el caso importa poco que la raíz del tema, que hace de segundo miembro, diese temas verbales: cauāre, dignāri, durāre, uidēre/uidēri, aptāre, odisse, cluēre, etc. $\mathrm{E}$ incluso tampoco importa nada que el mismo tema que hace de segundo miembro esté atestiguado como forma del verbo simple: ōsus, aerātus, èsus, meritus, ustus, datus, potens. Pues lo que no se conoció por lo menos antes del compuesto nominal es el verbo compuesto correspondiente: concauāre, condignāri, edurāre, euidieri, exaptāre, exōdisse, *incluēre, obaerare, obedīsse, obmereri, obūrere, perōdisse, pertaedere, *pertinere 'ser terco', *praedere/*praedare 'dotar', *praepotère. Por 1o tanto es evidente que el adjetivo que constituye su segundo miembro tuvo que entrar en tales compuestos en cuanto tema nominal y no verbal. 
Es decir, que tales compuestos por naturaleza fueron idénticos a los como perdulcis, permagnus, perpaucus, o como praeclärus, praediues, praelargus, o como subobscurus, subrufus, subrusticus; y naturalmente distintos de los como praecellens, praepollens, praeèminens, o de los como perculsus, perfectus, perterritus, o de los como excultus, expulsus, exterritus, etc. ${ }^{1}$. Y lo mismo y con más razón hay que afirmarlo de aquellos casos en los que el tema del segundo niembro no existió como tema verbal: adprìmus, adfabrēe, complüres, consūcidus, effēta, exalbidus, imbrutus, infacētus, insobrius, oblongus, oblüridus, obniger, obuncus, etc. ${ }^{2}$.

$\mathrm{Y}$ dentro de este grupo hay que incluir a inciens, una forma sobre 1a que existen muchos malos entendidos. Pues, en primer lugar, se suele creer que significó 'embarazada', cuando su sentido exacto, según se deduce de la tradición gramatical antigua y de su uso en los textos, no fue más que el de 'parturienta', 'la que está a punto de dar a luz y con los dolores del parto' (cf. Durius I, 1973, p. 227). Y sobre esta base se la suele dar como un derivado de *en-ku-iens, según se dice compuesto

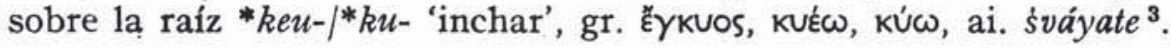

1 Incluyo aquí a obēsus, exōsus/perōsus y pertaesus, porque las formas personales de los compuestos respectivos (obēdi, perōdi, pertaedet), por su aislamiento y por la fecha tardía en que aparecen, tuvieron que ser formas secundarias, creadas sobre los participios perfectos y no el origen de éstos. Sobre pertaesus, en particular, cf., infra. Y lo mismo que de los anteriores hay que decir de obaerätus 'cargado de deudas' (ya en Varrón), que no pudo proceder de aeräre, desconocido fuera de los glosarios, ni de obaeräre, atestiguado por primera ve $\iota$ en Prisciano. Io cual prueba que no pudo ser más que un compuesto directo sobre aerätus, conocido ya por Varrón y Cicerón, y sin duda formado sobre aes, aeris, como cordātus sobre cord, cordis. Y lo mismo puede decirse de aduncus, atestiguado ya en Ter., concauos (en Finn.) y edürus (en Virgil.), frente a los verbos correspondientes atestiguados aduncäre en S. Agustín, concauāre en Ovidio y edürare en Tácito y Columela. Io cual indica que en todos ellos fue el compuesto nominal el origen del verbal, y no a la inversa. Sobre pertinax y sobre prasditus, cf. infra.

2 Por lo demás puede notarse que a concauos, Bader, op. cit., p. 325 le da como formación analógica de conuexus, y que Stolz-Leumann, $H$. Gr.e, p. 400, sin aludir expresamente a la analogia pone a los dos en el mismo grupo y como paralelos. Pero la analogia es muy difícil admitirla, ya que frente a concauos (en Einn. y Catón) comuexus no aparece hasta Cicerón. Por otra parte ya he indicado (Actas del $5 .^{\circ}$ Congreso Español de Estudios Cld́sicos, p. 10o) que conue$x$ us $<$ conuersus fue un derivado verbal. De modo que morfológicamente el paralelismo entre conuexus y concauos no es del todo exacto. $\mathrm{Y}$ lo mismo que de los anteriores hay que decir de compar, al que Stolz-Leumann, H. Gr.o. p. 400 , como he dicho, quiere dar como regresivo verbal de comparäre.

3 Asi Brugmann, Grund I', 280 y 321; Wiedemann, Lit. Praet. 138; Persson, $W z \epsilon r w$. , p. 289; y de manera parecida Sommer, $H b_{\text {.s. }}$ p. 249; Walde-Hofmann, $W b_{\text {.a. }}$ El que no se atreve a adoptar una actitud firme es Ernout-Meillet, $D E L L$. 
Pero esa etimología, en primer lugar, no da razón del sentido de la palabra, que como decimos fue, no el de 'embarazada', sino el de 'parturienta'. Aparte de que el sentido pasivo de grauida o 'embarazada' sería difícil de conciliar con un participio presente. $\mathrm{Y}$ sobre todo tiene el inconveniente de que en latín no quedó la menor huella, ni del compuesto en ${ }^{*} e n-k u$ - $-\hat{x} o$, ni siquiera del simple ${ }^{*} k u-i e o^{1}$ y por otra parte tampoco se ve cómo de ${ }^{*} e n-k u$-iens podría haberse pasado a inciens.

Como se explica con toda sencillez inciens = parturiens, es a partir

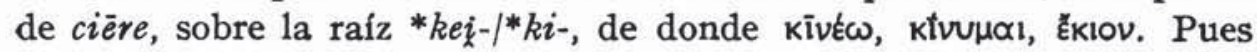
ciere, además de su sentido fundamental de 'agitar, mover', admitió una significación secundaria pero muy frecuente de 'impulsar, excitar, producir, provocar, dar origen o dar a luz': cière pluuias, imbres, nubila, nimbos, tempestates, frigora, fletus, lacrimas, terrores, furores, dolores; cière bella, simulacra belli, pugnas, seditiones, acies, strages, etc., y en particular en la lengua de la medicina: ciēre humōrem, ürinam, uomitus, pectoris excreatiōnes, sudörem, saliuam, ructus, uomitiones, etc. Se comprende pues que sobre su participio ciens 'la que está para dar a luz' se formase un intensivo inciens 'la que está con los dolores del parto'. Un intensivo precisamente, por las molestias y dolores que el parto suele llevar consigo (cf. el gemitus immanes ciens del mons parturiens de Fedro). De ahí el connixa, también intensivo de Virgilio, Eglog. I, 15, referida a la oveja o cabrâ que acaba de parir dos mellizos. Pero un intensivo formado directamente sobre el participio, y sin relación ninguna con un inexistente $*_{\text {inciere. }}$

Y lo mismo, aproximadamente, que de inciens hay que decir de infensus 'muy irritado', 'animado de sentimientos hostiles', al que se suele dar como un regresivo de *infendere (con la rafz * $g h^{*} e m$ 'golpear',

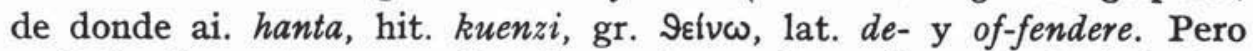
en latín, fuera de en un glosario, no hay más testimonios de infendere que un infensus est, Periochae II2, p. I08, probablemente una errata en vez de incensus est (cf. Liv. III 28,9). Y en último término, y aun dando como auténtico el infensus est, de los Periochae, es inconcebible que de un verbo, atestiguado una sola vez y en fecha tardía, hubiese podido salir el infensus, atestiguado ya en Plauto y de uso corriente en la lengua de todas las épocas. Hay, pues, que reconocer que infensus tuvo que ser una creación directa sobre el participio fensus de *fendere, supuesto por de- y of-fendere: de- y of-fensus.

1 Sobre la supuesta relación de -cundus con esa raiz (Benveniste, BSL 34, 1933. pp. 186-190), seguido por Bader, Composés Nominaux, p. 216), cf. EMERITA 15, 1947, p. 133 ss.

9 
$\mathrm{Y}$ lo mismo que infensus hay que enjuiciar aquellos compuestos nominales, de los que existió el compuesto verbal correspondiente, pero en época sensiblemente posterior al compuesto nominal. Pues, sin duda, dentro del orden lógico no es natural que la forma derivada apareciese antes que la primitiva, sobre todo cuando entre una y otra hay varios siglos de distancia. Así, por ejemplo, insignis 'distinguido, notable por algún distintivo, ilustre', atestiguado ya en Catón, Or. frg. 8, 2 y en Enn., sobre el que los gramáticos modernos se muestran muy indecisos. Pues Ernout-Meillet y Walde-Hofmann se limitan a apuntar su relación con signum, y lo que sobre esto se atreven a añadir StolzLeumann, $H . G r_{\cdot}$, p. 347 y el Thesaurus en forma vacilante es que debió de ser un regresivo de insignitus, atestiguado en Ennnio, y según ellos, derivado de insigne, -is 'nota distintiva', 'insignia', del que por lo demás no dan explicación. Ahora bien, es claro que insignìtus debió formarse sobre insigne, ya que insignire no aparece hasta época imperial. Pero esta hipótesis deja en la oscuridad el origen de insigne, que naturalmente tampoco pudo derivar de insignire. Problema por lo demás muy sencillo, pues sin duda insigne no pudo ser más que el neutro sustantivado de insignis, -e. Luego debemos suponer que el punto de partida del grupo tuvo que ser insignis, - $e$ 'muy señalado, muy distinguido', formado directamente sobre signum con el prefijo intensivo in-.

Desde luego que esto supone dos anomalias respecto al tipo normal de estos compuestos; a saber, el que aquí el tema base habría sido un sustantivo y no un adjetivo, y el cambio en tema en $-i$ del tema originario en $-o$. Pero desde el punto de vista morfológico la diferencia entre el tema sustantivo y adjetivo era insignificante; $y$ en griego se ve que formaciones análogas con $\varepsilon^{\prime} \nu$ se construyen indiferentemente sobre temas sustantivos (है้

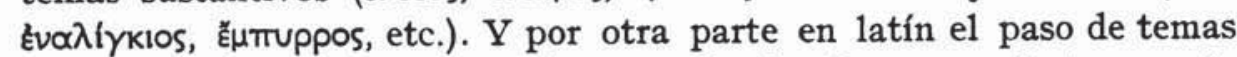
adjetivos en $-o$ a temas en $-i$ fue en todas las épocas corrientes y más

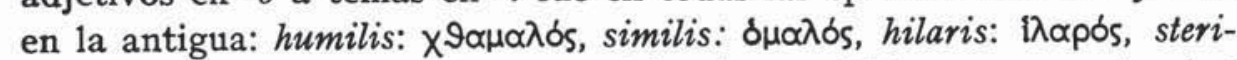
lis $<$ sterilus, fortis/forctis/forctus (glosado por PF 74, I4 por frugi et bonus) < horctus/forctus (glosado por PF 9I, I4 por bonus). Y además en insignis pudo estar favorecido por un influjo de su cuasi-sinónimo illustris. No parece, pues, que pueda darse importancia especial a estos detalles.

$\mathrm{Y}$ lo mismo que a insignis hay que interpretar a illustris "brillante, ilustre, esclarecido, famoso'. Forma a la que Stolz-Leumann, H. Gr.6, p. 203 y Ernout-Meillet, DELL se limitan a poner en relación con *lustrum 'purificación' y *lustrare 'iluminar' (considerados derivados de la

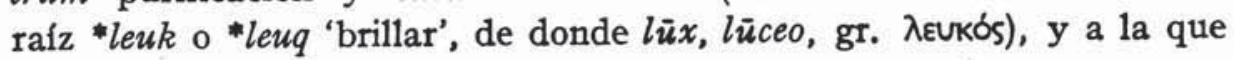


Walde-Hofmann y Stolz-Leumann, $H . G r \cdot 6$, p. 203, dan por un regresivo de illusträre, al parecer, según ellos, derivado de *leuis-trum/lustorare < *leuc 'luz', pero no precisan si tendría relac. con lüstrum 'purificación'. Etimología que desde luego semánticamente parece armonizarse bien, tanto con el sentido de illustris, como con el de los compuestos paralelos praelustris y sublustris (sin duda creaciones sugeridas por illustris). Aunque lo cierto es que sobre la base *leuk o*leuq no se ve (a pesar de lo fácilmente que se admite) cómo podría haberse desarrollado la $s$ interior. $\mathrm{Y}$ por otra parte resulta que el matiz de 'brillar' no aparece para nada en lustrum, lusträre. Todo lo cual parece indicar que el sentido de 'brillante', que los adjetivos del grupo adquirieron, debió ser un matiz que illustris recibió secundariamente por una etimología popular, que le relacionó con lux y que tal vez lustrum no procedió de la supuesta raíz *leuq. Lo que no parece que pueda negarse es la relación de illustris 'muy puro', 'muy limpio', 'muy claro', de donde 'brillante, luminoso', con lustrum 'purificación, ceremonia purificadora o expiatoria'. Pero el caso es que illustris está atestiguado ya en Plauto, mientras que illustrāre no aparece hasta la Rhet. ad Herennium. Lo cual quita toda fuerza a la hipótesis de Walde-Hofmann. Aparte de que, como luego indicaré, a partir de un verbo en -äre como illustrāre es sumamente dudoso que se sacasen regresivos con tema en $-i$. Por lo tanto hay que pensar que illustris no pudo ser más que un compuesto intensivo, formado directamente sobre lustrum; un compuesto idéntico a insignis sobre signum. El cambio de tema en $-i$ del en -o pudo deberse a una asimilación a otros temas adjetivos como terrestris, campestris, palustris.

$\mathrm{Y}$ un caso similar a los anteriores es el de adaeque atestiguado ya en Plauto, al que Stolz-Leumann, $H$. $G r_{.6}$, p. 400 , parece dar como regresivo de adaequāre. Pero frente al adaequus, supuesto por el adaequē de P1., adaequäre no aparece hasta Cicerón. Por lo tanto, y dado que el addio desde la época más antigua compuestos intensivos formados directamente sobre temas adjetivos (adprimus, adprobē, adpōtus, aduncus) hay que pensar que adaeque fue uno más de ellos, y no un regresivo verbal.

$\mathrm{Y}$ otro caso parecido al de adaeque es el de efferus, atestiguado ya en Accio, al que Brenden, p. 45, y de acuerdo con él Eirnout-Meillet y Walde-Hofmann dieron por un regresivo de efferäre (op. cit., p. 45)

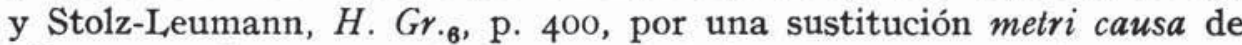
efferäta < efferāre. Pero la cosa es que de ferāre no hay en latín el menor indicio, y que efferäre no aparece atestiguado hasta Cicerón. Lo cual obligaría a suponer la anterioridad cronológica (aunque no sea muy con- 
siderable), del supuesto derivado sobre el primitivo. Frente a esto se ve que la formación directa de compuestos intensivos con ex sobre temas adjetivos fue conocida en latín (ēdūrus, ègelidus, èuidens, exōsus, etc.). Luego debemos pensar que efferus fue un compuesto directo sobre ferus, y efferāre un derivado suyo, a la inversa de lo que se suele suponer.

$\mathrm{Y}$ dentro de esta serie hay que incluir a incuruos, atestiguado ya en Ter. Eunucus 336, según Donato, y supuesto por el incuruiceruicus de Pacuv., Trag. 408. Forma que Niedermann, IF 26, 1909, p. 54, y Brender, p. 45 , y de acuerdo con ellos Ernout-Meillet, $D E L L$ y StolzLeumann, H. Gr.6, p. 400, y Svennung, Unters. zu Palladius, p. 576, y Bader, p. 379, y el Thesaurus, quisieron derivar de incuruāre, atestiguado en Catulo y Cicerón. Lo cual significa una antigüedad de la forma supuesta derivada (incuruos) respecto a la supuesta primitiva (incuruäre). Y a esto se añade que el incuruāre, supuesta base de incuruos, aparece atestiguado antes que el simple curuāre, al parecer obligada base de incuruāre, y que no aparece hasta la época augústea. Lo cual deja en el aire ese supuesto origen de incuruos. Y de ahí que algún autor, el Thesaurus, y según éste Leumann ${ }^{1}$ han creído que incuruos pudiese derivar más bien de incuruescere (Ënn., Scaen. 153). Pero a su vez ocurre que incuruesco es por decirlo así un hápax, pues sólo aparece en dos citas del pasaje de Ennio (Cic., de orat. III I54 H. y Non., p. I76). Y además resulta que la base al parecer obligada de incuruesco, es decir, curuesco, no aparece documentada hasta Ammiano. Lo cual obliga a suponer que incuruesco no pudo salir más que de incuruos. $\mathrm{Y}$ por encima de cualquier otra razón, ocurre que un regresivo incuruos $<$ incuruesco representa un tipo de regresivos desconocido en latín y griego. Esto no suelen reconocerlo los gramáticos modernos, porque sobre el pie forzado de que ni en griego ni en latín hubo compuestos nominales con prefijo intensivo, no han encontrado más camino para explicar tales formas que reducirlas a regresivos sin reparar en nada. Pero en latín, y lo mismo en griego, los regresivos se sacaron de la forma completa que el verbo tuvo en el presente de indicarivo: coquus, condus, prōmus, anhēlus, inuidus, prouidus, resonus, delìrus, degener, aduena, convena, conuiua, scriba, accola, incola, etc. Frente a esto es claro que una forma como incuruos se explica sencillamente como un compuesto intensivo sobre curuos. Luego debemos pensar que fue así como se formó, y que incuruāre e incuruescere no fueron en su origen más que

1 La referencia no sé de dónde pudo tomarla Hofmann; pero en el Thesaurus veo que s. $u$. incuruus, este dice: $a b$ incuruescere potius deriuut Leumann. 
unos derivados suyos. Unos derivados de los que posteriormente debieron extraerse el curuāre y el curuescere.

$\mathrm{Y}$ otro caso de características muy parecidas a incuruus es incānus, atestiguado desde $\mathrm{P} 1$., al que los gramáticos modernos vienen dando desde Stolz, Hist. Gramm., p. 403, como regresivo de incänescere. Asf́ Niedermann, $I F$ 26, I909, p. 53; Brender, op. cit., p. 50; Ernout-Meillet, $D E L L$; Walde-Hofmann, $W b_{. s}$; el Thesaurus; Bader, op. cit., p. $38 \mathrm{r}$; al parecer Svennung, Untersuch. zu Palladius, p. 576; y así, al parecer, Stolz-Leumann, aunque este demuestra una cierta inseguridad. Pues mientras que en $H$. Gr.5, p. I96, le daba expresamente como regresivo de incänescere, en $H$. Gr.5, p. 400, le incluye sólo en un grupo de compuestos, de los que prudentemente dice que muchos fueron regresivos, sin remitir para nada a incānescere. Donde expresamente remite a incānescere es en p. 268. Pero incānus, como he dicho, está atestiguado ya en P1., Rudens I26, mientras que incānesco no aparece hasta Virgilio. Bastaría, pues, sólo esto, para dar por inválida esa opinión, al parecer hoy día general. Pero ya digo que además y con independencia de esto, un regresivo como incänus < incānescere representa un tipo morfológico desconocido en latín. No queda, pues, más salida que reconocer que fue una formación directa sobre cānus con el prefijo intensivo in-.

$\mathrm{Y}$ en la misma línea que incuruus e incānus hay que colocar algunos casos de época tardia, como impinguis (S. Clem., ad Cor. II 2, y Hegesias III 26, 2), infrigidus (Orib., Eup. 2, I Q XXVIII, p. 5I6) e irraucus (Plin. Val. I, 2 Reb.). Formas que diversos autores han querido dar como regresivos de impinguescere, infrigidiscere e irraucescere. Así, respecto a irraucus Brender, op. cit., p. 50; y respecto a infrigidus e impinguis Svennung, Untersuch..., p. 576 , que también insinúa la posibilidad de que impinguis fuese regresivo de impinguäre, e infrigidus de infrïgidäre; y respecto a todos ellos el Thesaurus, quien admite a su vez las posibilidades apuntadas por Svennung y el que irraucus procediese de irraucire. Pero con independencia de que existiesen o no los verbos respectivos, el hecho es que ni en latín ni en griego hay ningún ejemplo seguro de que se diesen regresivos de ese tipo; es decir, con pérdida del sufijo del tema de presente. Hay pues que rechazar categóricamente que ninguno de esos compuestos nominales procediesen de verbos en -scere.

Por cierto que esta dificultad la han entrevisto, de manera más o menos vaga, los autores. $\mathrm{Y}$ de ahí las vacilaciones del Thesaurus y de Svennung sobre si no habria que partir en todos los casos de verbos $\sin$-sco. Idea que en lo que se refiere a impinguis ha tenido una acogida 
muy favorable, pues la aceptaron entre otros, Hey, GGA, 1909, p. 341; Walde-Hofmann, $W b_{\cdot 3}$, y más modernamente Bader, op. cit., p. 382; Svennung, p. 576 y Stolz-Leumann, $H . G r_{6}$, , p. 400 . Pero ya indicaré a continuación que la derivación impinguis < impinguäre tropieza, a su vez, con un obstáculo insalvable; a saber, la forma en -is del supuesto regresivo en -is sobre un tema en -äre. Y por lo demás yo tampoco creo que de verbos en -ire como irraucire se sacasen regresivos en -us, $-a,-u m$ como irraucus. Aparte de que es dudoso que hubiese existido en latin el verbo irraucire (cf. el Thesaurus). E1 único ejemplo que queda en cuenta es infrigidus, que desde luego se ajusta al tipo corriente de los regresivos, a partir de infrigidäre, verbo bien atestiguado (Schol. Iuuen., Pseudo August., Philarg. med., Pseudo Soranus, Oribas., Alex. Trall., etc.). Pero a finales del imperio veremos que la formación directa de compuestos con in- sobre temas nominales experimentó un cierto rejuvenecimiento, sin duda por imitación de compuestos antiguos, que habian sobrevivido en la tradición literaria. $\mathrm{Y}$ en Oribasio el infrigidus corresponde al gr. úmó $\psi u x p o s$. A mí, pues, todo me induce a pensar que el infrigidus fue simplemente el resultado de dos fuerzas, la tendencia en algunos autores tardios a revitalizar los antiguos compuestos intensivos con in-, y la expresión en griego de la misma idea por un compuesto como vimóyuxpos, de naturaleza idéntica, como veremos, a los compuestos latinos con in- y sub-.

$\mathrm{Y}$ a la luz de estas conclusiones hay que enjuiciar otra serie de compuestos nominales, con preposición en función no local, y con un adjetivo en -idus como miembro final; por ejemplo, exalbidus (Plin.), exāridus (Tertul.), expallidus (Suet.), expauidus (Liv.), ēuänidus (Ovid.), èualidus (Cic.). Formación esta (la de los adjetivos en -idus), que se desarrolló en general en dependencia íntima con los verbos de estado en -ère: är-ēre: -idus, flōr-ēre: -idus, frìg-ēre: -idus, lüc-ēre: -idus, pall-ēre: -idus, etc. Lo que ocurrió fue que muchos de los verbos de estado en -ëre, además de los adjetivos en -idus, tuvieron al lado otro verbo incohativo en -ēsco: albēre, -ēsco: idus, ärēre, -ēsco: -idus, flōrēre, -ēsco: -idus, frīgère, -èsco: -idus, pallère, -èsco: -idus, pauēre, -ēsco: -idus, ualēre, -èsco: -idus, etc. Y sobre esa analogía se llevó el mismo paralelismo de los simples alb-èsco: alb-idus, àr-ēsco: är-idus, etc. a los compuestos con -èsco pero sin -ère: exalb-ẽsco: -idus, exār-ēsco: -idus, èual-ēsco: -idus, èuān-ēsco: -idus, expall-ēsco: -idus, expau-ēsco: -idus, etc. Aquí externamente parece como que la formación en -idus se sacase directamente de los en $-\bar{e} s c o$, pero en realidad el hecho se debió al influjo que sobre los compuestos ejercieron los simples en -èsco. O lo que es lo mismo que la raíz del fenómeno consistió en una analogía y no en un proceso 
regresivo, propiamente dicho, como suele creerse. Por cierto que arraigada en un grupo de compuestos, la formación pudo extenderse a veces a otros casos por una asimilación de segundo grado, sin necesidad de que en el simple existiese ni el compuesto en -ère, ni la forma en -idus. Así, por ejemplo, ēuānidus sin necesidad del doble *uānidus ni del *euānēre ${ }^{1}$.

Y a propósito de los regresivos hay que tener en cuenta otro detalle, al que tampoco se ha prestado la debida atención. Y es que la formación a que se ajustan los claramente regresivos se reducen a unos tipos muy limitados. Así, aparte del grupo de masculinos en - $a$, como aduena, conuena, accola/incola/agricola, conuiua, scrība, etc., sin duda influidos por el etrusco, algunos femeninos de tema en $-\bar{a}$, como pugnā, luctā, Suadā, etc., y sobre todo el grupo de los temas masculinos en -os, como condus, coquus, prōmus, prouidus, inuidus, resonus, etc. ${ }^{2}$.

Desde luego que al lado de estos hay algunos regresivos con tema en $-i$, sacados al parecer de verbos en -äre. Algunos regresivos, no muchos. La prueba es que Leumann, $H$. Gr., p. 346 , no documenta su afirmación más que con tres ejemplos: transformis, effrēnis, rebellis. Aunque tal vez el grupo pudiera alargarse con algún que otro ejemplo más, como inclinis: inclinäre, acclinis: acclinäre. Pero de cualquier forma se ve que se trata de casos excepcionales. $Y$ de casos que se explican

1 Lo mismo que a veces pudo darse un compuesto en -idus sin necesidad del verbo correspondiente. Asi exsūcidus (Tertul.) salido sin duda de sũcidus por simple analogia de exäridus: äridus, eualidus: ualidus, expauidus: pauidus, expallidus: pallidus, etc.

2 Y así a lo que creo concinnus 'bien arreglado o dispuesto, armonioso, bien hecho o proporcionado'. Voz sobre la que existen muchas dudas entre los autores, y que sin duda no parece que pudiera ser más que un regresivo de concinnāre. Por lo menos se ve que el sentido de concinmus se corresponde perfectamente con el de concinnäre 'preparar o mezclar en las justas proporciones, disponer armónicamente, arreglar con arte' ( $P F$, p. 33, 25: apte componere). El problema al parecer más oscuro es de dónde podría haber salido concinnāre. Pero a mi me parece que el sentido de concinnäre se armoniza a su vez perfectamente con el de concinere 'cantar juntos, cantar al unísono, cantar armoniosamente', cf. Cic., Nat. Deor. II 7, 19: mundi partes inter se concinentes; ibid. I 7, 16: Stoici cuin Peripateticis re concinere uidentur, uevbis discrepare, etc. $\mathrm{Y}$ por supuesto el paso de un concinere a *oncināre se ajusta a un tipo morfológico muy corriente en latín: accumbere: accubäre, dīcere: dicāre, dücere: ēducare, lauere: lauäre, consternere: consternäre, oppetere: optāre, confligere prōflīgāre, etc. Lo mismo que la geminación de la $-n n$ - está de perfecto acuerdo con el sentido intensivo de concinnäre. Todo, pues, lleva a que concinnāre fue una formación sobre concinere, de la que en un proceso ulterior se sacó el concinnus. Así ya Stolz-Leumann. $H$. Gr. o, pp. 368 y 398 , aunque él deja en la oscuridad el origen de concinnäre. 
sencillamente, si se tiene en cuenta que la $-i$ final fue nota característica de una multitud de adjetivos (cf. lo dicho en p. I26); en particular de adjetivos compuestos con la partícula privativa in-: illimis, imbellis, imberbis, infämis, inermis, etc., y con prefijos de separación o privativos: abnormis, dēclīuis, dēformis, èlinguis, èlumbis, ènōdis, extorris, exossis (al lado de exossus), etc. Ahora bien, los regresivos esos fueron también compuestos con prefijos que externamente tenían un gran parecido con esos otros compuestos. $\mathrm{Y}$ aparte de esto resulta que al lado de todos ellos existieron compuestos con - $i$, o de la misma raíz o al menos semánticamente afines a ellos. Por ejemplo, informis y deformis al lado de transformis; accliuis, dēcliuis y procliuis al lado acclinis, inclinis; y hostis y perduellis al lado de rebellis; y al lado de effrēnis el grupo citado de los con $e x$ - con sentido privativo. No tiene, pues, nada de particular que el $-o$, que debería esperarse normalmente en las formaciones regresivas, y que en effrènus fue corriente al lado de effrènis, se viese sustituido por $-i$ por analogía de esas numerosas formas con $-i$ afines ${ }^{1}$.

Pero claro está que este resultado anómalo no se puede admitir cuando al lado del compuesto con - $i$ existió con anterioridad a él el simple también con $-i$. Es decir, que existiendo pinguis, es ilógico suponer que el impinguis fuese regresivo de impinguäre. Así Walde-Hofmann, $W b_{\cdot 3}$ y Stolz-Leumann, $H . G r_{\cdot 8}$, p. 400 , y el Thesaurus, y Bader, etc. Es una falta de lógica, porque dado que el in-tuvo un valor intensivo, el compuesto se explica sencillamente a partir del simple, mientras que la formación regresiva supondría una anomalía sin justificación posible. Aparte de que impinguäre fue un verbo de un uso rarísimo. Lo que aún haria más inverosímil la hipótesis de que sirviese de base para formaciones nuevas. $\mathrm{Y}$ por la misma razón entiendo que igualmente hay que excluir el que adsimilis, atestiguado ya en P1., Merc. 957, fuese un regresivo de adsimuläre (Stolz-Leumann, $H . G r \cdot B$, p. 400). Lo más que en teoŕa pudiera pensarse es que fuese una creación analógica sobre adsimuläre, según el modelo de similis: simuläre (asi Brender, op. cit., p. 48). El que ciertamente debió formarse sobre abhorrēre o aborrescere debió de ser abhorris: scandalosus, de CGL V, p. r6I, II y V, p. 49I, 44; pero, como indicó también Brender bajo el influjo de modelos como putris: putrēre o putrescere, mitis, mìtescere, pinguis: pinguescere.

$\mathrm{Y}$ por la misma razón es imposible que èneruis 'enervado, sin fuerzas' (de Hor., Val. Max., Séneca, etc.), y ènōdis 'sin nudos' (de Virg., Plin.

1 $\mathrm{Y}$ asi también pudiera explicarse exossus, probablemente regresivo de exossāre, en sustitución del esperado exossis. 
etcétera), pudiesen ser regresivos (como creyó Brender, p. 48) de èneruãre, ènodāre, aunque estos verbos estén atestiguados en fechas anteriores a los adjetivos. Y más imposible aún el que contristis (ya en Ter., Ad. 865), fuese regresivo, como también creyó Brender, loc. cit., de contristäre, no atestiguado hasta Rutilio Lupo y las Epist. ad Cicer. Es decir, que èneruis y ènōdis tuvieron que ser compuestos del mismo tipo que enormis, èlinguis, etc., y contristis un compuesto intensivo del mismo tipo que compar, consūcidus, condignus, etc.

Más aún, hoy día, bajo el prejuicio de que sobre temas nominales no se formaron compuestos intensivos con prefijo, la opinión generalmente admitida es que, cuando en la fecha en que se creó el compuesto nominal existió ya el compuesto intensivo verbal, aquél tuvo que ser un regresivo de éste. Pero probado que muchos compuestos nominales tuvieron ese origen, que hoy no se quiere reconocer, se comprende que ese principio no se puede utilizar indiscriminadamente y sin precaución. Ni siquiera en los casos en que morfológicamente no hay ningún obstáculo para que el compuesto nominal derivase del verbal. Y ni siquiera en los casos en que el compuesto verbal es algo anterior al nominal, sobre todo si la diferencia cronológica entre ellos no es muy notable. Pues dado que ambas formaciones fueron legítimas y normales, en teoría es perfectamente posible que cada compuesto se formase con independencia del otro, e incluso que el nominal fuese origen del verbal. Y de hecho hay casos que parecen abonar esta hipótesis.

Por ejemplo adprobus, supuesto por adprobē ya en P1. al lado de adprobäre. Lo cual ha sido causa de que en general se le considere un regresivo verbal, aunque el Thesaurus lo deja algo dudoso. Pero según los gramáticos adprobus tuvo para los latinos un sentido de valde probus (cf. Gel. VI 7,8), que en adprobäre 'dar por bueno, aprobar' está algo desvanecido. A mí, pues, me produce impresión de que los dos compuestos pudieron formarse de manera independiente. $\mathrm{Y}$ algo parecido hay que decir de condensus, atestiguado en Lucrecio siete veces, al lado de un condensēre, único en toda la literatura, y de un condensãre, también en época de Varrón único, aunque éste sobreviviese en otros autores posteriores. Pero a mí esta diferencia tan grande entre el uso en sus orígenes del adjetivo y el de las formas verbales me lleva a pensar que fue el compuesto nominal el origen de las formas verbales, y no a la inversa como se suele creer; y en particular que condensus no pudo proceder de condensēre, como dice Stolz-Leumann, $H$. Gr.6. p. 400.

$\mathrm{Y}$ de manera parecida veo yo la relación entre praediuinus 'adivino, profeta' y praediuināre 'adivinar', atestiguados ambos por primera vez en Plinio. Caso este en el que también se suele considerar al compuesto 
verbal origen del nominal. Pero la acepción de 'adivino, profeta' estuvo en dĩuinus muy desarrollada desde fines de la república. Y Plinio fue entre los prosistas del imperio el que mostró una predilección más marcada por los compuestos nominales intensivos con prae. No tiene pues, nada de extraño que el praediuinus no fuese más que una manifestación de esa tendencia, con independencia de praediuinäre, que pudo ser una construcción paralela independiente $o$ tal vez incluso derivada de la forma nominal.

Más aún, a mí me parece muy dudoso que dos solos ejemplos de immadidäre en S. Ambrosio constituyan una prueba sin más de que immadidus (Avieno) fuese un regresivo suyo (asi Brender, p. 45). Yo me inclinaria más bien a pensar que immadidus fuese una formación analógica sobre immadesco (mucho mejor atestiguado), según infrigidus: infrigidisco, expauidus: expauesco, etc., o un compuesto directo sobre madidus. Aparte de que por lo demás pudo estar sugerido por el gr. turypos.

Ahora bien no se puede negar que en casos como los de este último grupo es sin duda difícil llegar a conclusiones seguras. Pero aparte de estos quedan entre los analizados un conjunto de hechos, sobre cuya naturaleza no parece que quepan dudas. $\mathrm{Y}$ esos hechos están confirmados por los casos anteriormente citados, en los que el segundo miembro fue un tema nominal sin relación ninguna con temas verbales, como adfabrē, adprīmus, adprīmē; o como condignus, compar, complüres, consimilis, contristis, consūcidus, o como èdūrus, ègelidus; o como obdürus, obniger, oblūridus, obuncus, etc. A los que pudieran añadirse una serie de formas transmitidas por los lexicógrafos, como congrätus, consänus, conrūdis, consolidus, consuäuis, etc., y otros de época tardía como adcopiösus adfuluus, adūber; èdocilis, ègloriōsus; y en particular el grupo relativamente numeroso de los compuestos tardíos con in, aparte de infrigidus, immadidus, impinguis, irraucus, ya citados.

Por ejemplo, imbrütē =immaniter (Fulgent. p. I68, I4 Helm.), imbenignus = muy benévolo (CE, CIL VIII 13134), indēbilis, supuesto por el fr. ant. endieble, esp. endeble, indignus = ualde dignus (Pseud. Ascon., Epigr. 129), y de ahi indignatio (Avell. 97,27 y CIL I782), infacètus = ualde facetus (Oh blandos oculos atque infacetos, Anth. lat. 7r4), inopimus = muy rico o abundante (inopima satietas, Oros. III 5,3), inquiètus = muy tranquilo (Permane inquietus, Didascal. apostol. 39, 27, párr. 43 Heuler: ìoúxios), insobria = muy sobria $(C E, \mathbf{1 6 2 2}, 5)$. Casos todos, por cierto, sumamente significativos. Pues claro está que, si el uso no hubiese venido de antiguo sería inconcebible cómo podría haberse desarrollado en la época más tardía del latín. Que fue sin duda 
1a razón de que Svennung, Untersuch., p. 574 ss., se resistiese a admitir en ellos un valor intensivo; a saber, su creencia de que el latín más antiguo no había conocido este tipo de formaciones. Pero que el contexto exige en todos ellos un sentido intensivo es evidente, como vieron entre otros Heuler, Sitzungsber. d. Wien. Akad. der Wissensch., p. 134, 1896, XII, párr. 36; Loefstedt, Beiträge, p. II7, y Niedermann, $I F$ 26, I909, p. 54. Y que formaciones de ese mismo tipo existieron en el latín más antiguo ha quedado demostrado por los ejemplos citados anteriormente. Luego debemos concluir que ese uso más tardío no fue más que un eco de una tradición antigua, conservada viva a través de la literatura ${ }^{1}$.

Lo que pudiera objetarse es que los ejemplos de los siglos finales del imperio, e incluso los de los siglos primeros del mismo, tienen un valor probativo algo dudoso, por lo menos respecto al uso en la lengua diaria de la conversación. Pues en el imperio es muy probable que en la lengua viva del pueblo, fuera de per- y $s u b$-, las demás preposiciones hubiesen perdido su capacidad para dar compuestos nuevos. $\mathrm{Y}$ algo parecido puede decirse de los ejemplos transmitidos por los lexicógrafos sin comprobación en los textos vivos. Pues los lexicógrafos parece ser que desarrollaron por su cuenta una cierta actividad etimologizante, que les llevó a veces a inventar compuestos intensivos o regresivos que nunca existieron. Aunque en general hay que pensar que la mayoria de los compuestos que nos dan debieron encontrarlos en la literatura hoy perdida. Y desde luego que, si los autores literarios siguieron creando compuestos intensivos con esas preposiciones cuando el procedimiento había dejado de ser usual en la lengua viva, tuvo que ser porque el procedimiento había quedado consagrado en la literatura anterior; porque encontraron huellas de tales formas en los autores de épocas anteriores. Nada más que por eso. Es decir, que por eruditas, artificiosas y anacrónicas que tales formas tardías puedan ser, constituyen una prueba de que en una época antigua fueron normales. $O$ lo que es lo mismo, confirman las deducciones que hemos sacado en las páginas anteriores. Deducciones que a su vez están confirmadas por los grupos de compuestos más numerosos, los con per-, prae- y sub-, y además como veremos por los hechos análogos de otras lenguas como el griego. Todo, pues, indica que la formación de compuestos intensivos por la unión directa de las más diversas preposiciones a temas nominales fue un procedimiento natural y normal.

1 Y lo mismo que de éstos hay que decir de los compuestos con ex de los autores tardios y de los glosarios, como èlüculentus (luculentus), excruentus (Pass. ('yr.), èdocilis, effēcundus, ēgloriōsus, etc. 
E1 problema que surge ante esta conclusión es cơmo unos elementos como los adverbio-preposiciones, que por esencia indicaron una relación local, podrían, en aposición a un tema nominal, haber convertido su sentido propio en uno intensivo. Pero eso en el caso del per- era muy natural, por lo menos en las formas nominales de verbos compuestos. Pues su significado de 'a través de' y 'a lo largo de' referido a ideas verbales, llevaba anejo un sentido secundario de 'esfuerzo', o a veces de 'acabamiento' ('todo a lo largo hasta el fin'), que en el fondo se confundía con el sentido intensivo. $\mathrm{Y}$ de hecho se ve que efectivamente, tanto en latín como en las lenguas emparentadas, es muy corriente que los verbos con per- o la forma correspondiente de esta en cada lengua, tengan un matiz intensivo muy claro. Por ejemplo, en latín peragere 'llevar hasta el fin', percellere 'herir o golpear fuertemente', percipere 'coger o abarcar en conjunto o completamente', percolere 'cultivar con esmero', percutere 'golpear fuertemente', perdocère 'enseñar por completo', perdūcere 'llevar hasta el fin', perficere 'terminar', perfringere 'romper por completo', 'hacer añicos', perfundere 'derramar un líquido por completo', permanère 'quedar fijo en un sitio', permetiri 'medir o recorrer por completo', permiscēre 'mezclar o desordenar completamente', permouère 'agitar fuerte o profundamente', perpetrāre 'realizar algo costoso, realizar algo con esfuerzo', perrumpere 'penetrar con violencia', persequi 'seguir ininterrumpidamente', 'seguir sin descanso', persolueve 'pagar completamente', perspicere 'observar atentamente', personare 'resonar con estruendo', perstāre 'mantenerse firme y obstinado', perterrère 'asustar fuertemente', perturbäre 'producir una gran confusión', etc. (cf. Stolz, "Per und Anhang», $A L L$ 2, I885, p. 49 ss.).

Ahora bien es claro que ese matiz intensivo tuvo que pasar a los participios y derivados nominales de los verbos. Y naturalmente, dado el gran número de éstos, se comprende que por analogía la formación se extendiese a otros temas nominales, sin necesidad de que tuviesen relación con un verbo compuesto con per-. Es decir, que según dobles como actus: peractus, factus: perfectus, mixtus: permixtus, territus: perterritus, etc., se comprende que sobre cualquier clase de adjetivos se formasen compuestos como peramicus, pergrätus, permagnus, permultus, perpaucus, etc. No sólo esto, sino que, creado un grupo importante de compuestos nominales de este tipo, se comprende que a su vez se convirtiesen en focos de nuevas extensiones analógicas de segundo grado. Esto lo vio ya Brugmann, Grundr. $\mathrm{II}_{2}$, p. $79 \mathrm{I}$ y Stolz, $H$. Gr., p. 397; y lo han aceptado entre otros Walde-Hofmann, $W b_{.3}$ II, p. 285 y Bader, op. cit., p. 366 . 
Pero un proceso de intensificación semántica parecido al que presentan los compuestos verbales con per-, se da también en los compuestos verbales con esas otras preposiciones, que dieron origen a los compuestos nominales intensivos. Esto lo entrevió ya Woelfflin, Philologus $34, \mathrm{r} 876$, p. I ss. Y lo reconoce, siguiendo las indicaciones de éste, Schmalz-Hofmann-Szantyr, Synt., p. 297. Donde, por cierto, se observa certeramente cómo la intensificación quedó muchas veces oscurecida y enmascarada por el fenómeno inverso de la debilitación semántica que la siguió. Así igualmente Marouzeau, Traité de Stylistique, p. I3o. Por lo demás Szantyr notó también cómo la tendencia a la intensificación y al refuerzo de la expresión se dejó sentir sobre todo en la lengua popular, ya desde la época más antigua del latín. Pero lo cierto es que el resultado a que dio lugar esa combinación de fuerzas contrarias es un tanto confuso y apenas ha sido estudiado. Por ejemplo, los autores no han explicado de manera precisa, fuera de en el caso de los compuestos con per-, el mecanismo de cómo esos cambios semánticos se produjeron. $\mathrm{Y}$ de ahí que tampoco se haya visto la importancia que el fenómeno tuvo, y el que muchos hechos relacionados con él hayan pasado inadvertidos $^{1}$.

1 Es muy significativo a este respecto el caso de inuidère 'odiar', al que se atribuye como sentido originario el de 'mirar con los ojos torcidos', y que según se cree habría tenido en su origen, en la creencia antigua de que el mirar asi producia mal de ojo, traía la desgracia. Asi el Thesaurus, Eirnout-Meillet y WaldeHofmann. Pero con independiencia de que los ide. creyesen o dejasen de creer en el mal de ojo, lo cierto es que entre la idea de mirar 'con los ojos torcidos' y el valor local de in- hay un abismo semántico dificil de salvar. Como se explica sencillamente el sentido de 'odiar' y su equivalente, el de 'mirar con malos ojos' es a partir de inuidere 'mirar fijamente, clavar los ojos en uno'. Pues el 'clavar los ojos en uno' con expresión amenazadora ha sido siempre, desde los tiempos más remotos hasta nuestros días, una de las formas más naturales y fuertes de expresar odio. Una de las formas más naturales, porque en el fondo no es más que el reflejo espontáneo del hombre o la bestia heridas, dispuestos a caer sobre el objeto de su cólera. Y puesto que el in- tuvo la propiedad de reforzar la idea verbal, hay que suponer que fue ese el origen de inuidère. Por cierto que esta relación entre la idea de 'mirar fijamente' y el sentido de inuidère la entrevió ya Cic., 1 uscul. II 20: nomen inuidiae... dictum est a nimis intuendo fortunas alterius. Aunque hay que suponer que él debió encontrar esta etimologia en la tradición lexicográfica (Elio Estilón o Varrón).

$\mathrm{Y}$ otro ejemplo de caracteristicas parecidas a las de inuidère es ignoscere. Forma que ya Buecheler, $K l$. Schr. II, p. 59 y Woelfflị, $A L L$ I, 1884, p. 385 y Ascoli, Vorl. I 82, etc., hablan considerado un compuesto de in más gnosco, pero sin lograr explicarle satisfactoriamente. Lo cual llevó a Wackernagel, Symbolae phil. Danielsson, pp. 383-390 a relacionarle con ai. anujnā- 'concèder, perdonar'. Hipótesis dada por definitiva por Leumann (Glotta 23, 1924, p. I4I y cino- 
Pero con independencia de cómo el fenómeno se produjo, es claro que cuando los gramáticos latinos hablan de la uis intentiua de las preposiciones in compositione, se refieren lo mismo a los compuestos nominales que a los verbales ${ }^{1}$.

$\mathrm{Y}$ de hecho, y cualquiera que fuese su causa, se ve que en muchos de los verbos compuestos con prefijo, resalta, frente a los simples correspondientes un valor intensivo claro, parecido al que se observa con los compuestos con per-. Así, por ejemplo, entre los compuestos con ad-: accürāre 'preparar o cumplir con todo cuidado', adamäre 'amar mucho', adbibere 'beber con avidez', adigere 'forzar, obligar, llevar con violencia', adiūrāre 'jurar solemnemente', admīrāri 'contemplar con sorpresa o admiración', adnitī 'apoyarse con fuerza' (al lado de connìtī, èniti, inniti), appetere 'dirigirse con fuerza, desear ardientemente' (al lado de oppetere y optäre), attendere 'tender con esfuerzo hacia algo' (al lado de contendo, extendo, intendo), attonāre 'atronar, aturdir', etc.

$\mathrm{Y}$ asi entre los compuestos con con-: combibere 'beber mucho, absorber', confirmāre 'dar nueva fuerza', commōuèere 'agitar o mover fuertemente', complëre 'llenar por completo, colmar' (al lado de explère, implère, opplēre), comprimere 'oprimir, aplastar' (al lado de opprimere), concidere 'cortar en trozos, matar' (al lado de occidere), concinnāre 'mezclar o arreglar armoniosamente o en proporciones justas' ${ }^{2}$, concitäre 'excitar mucho' (al lado de excitāre, incitäre), concupiscere 'desear ardien-

mon 13, 1937, p. 33) y aceptada por Bader, p. 49, pero que los autores posteriores han rechazado, sin duda con razón, (cf. la crítica a la misma de Walde-Hofmann, s. u. ignosco). Los que han enfocado el problema de manera más acertada han sido Walde-Hofmann, y sobre todo Ernout-Meillet, quienes han visto que el sentido de 'perdonar' de ignoscere < in más gnōscere debió ser un desarrollo de la idea de noscere causam. Lo que en relación con el latín me parece que prueba poco el ejemplo citado por Hofmann del alemán nachsehen jemandem etwas, por naturaleza distinto del ignoscere latino. Lo definitivo, como apunta ErnoutMeillet es que ignoscere por su estructura fue un intensivo. Pero el sentido correspondiente a un verbo de esa estructura tuvo que ser, no el de 'tratar de conocer la causa', como dice Ernout-Meillet, sino el de conocer muy bien las causas de lo ocurrido. Idea de la que fluye, naturalmente, la de 'considerarlo justificado o disculpable'. Creo, pues, que debió ser ese el origen de ignoscere.

1 Cf. los pasajes ya citados (fol. 2) confirmados machaconamente en lo que atañe a in- por PF. Así, p. 48, 17 L: "in» enim saepe augendi causa addicimus, ut inuocauit, inclamauit; y 96, I: "in" non semper "abnuitionem" significat, sed etiam pro "adnuendo" ponitur, ut inuolando, inclamando, inuocando; y 97, 15: *in praepositio modo signiticat quod "non"... modo auctionem ut "inclamauit".

2 La prueba de que los latinos le sintieron como intensivo es la geminada -nn-, sin duda de carácter expresivo, como he indicado más arriba. 
temente', conficere 'hacer por completo, terminar, matar' (al lado de efficere y perficere), conqueri 'quejarse amargamente', consequi 'seguir con ahínco, dar alcance', consōlāri 'reconfortar, aumentar el ánimo, hacer firme' 1 , consternäre 'hacer completamente llano, aplastar', contendere 'extenderse con esfuerzo, esforzarse', contundere 'machacar golpeando, destruir', corripere 'arrebatar con rapidez', etc.

$\mathrm{Y}$ entre los con ex-: exardescere 'abrasarse, estar devorado por el fuego', excitāre 'hacer salir, hacer levantarse', excolere 'cultivar con esmero', excoquere 'cocer mucho, abrasar', excruciäre 'atormentar, martirizar', exedere 'comer del todo, devorar', exoptāre, intensivo de optāre 'desear vivamente', exornāre 'ualde ornare', expauescere 'horrorizarse, sentir horror', explère 'llenar del todo, saciar', expugnare 'tomar por las armas, a viva fuerza', exsecräre 'llenar de maldiciones', exequi 'cumplir o ejecutar por completo', exsuperāre 'sobresalir mucho', extenuāre 'hacer muy delgado', exterrēre 'aterrorizar, ahuyentar asustando mucho', extinguere 'apagar el fuego rociándole con agua', 'apagar el calor vital, matar' $^{2}$, exürere 'quemar o desecar por completo', extorquēre 'arrancar con violencia', extrūdere 'echar fuera a empellones', exturbāre 'arrojar fuera con violencia', exultäre 'saltar locamente', etc.

1 Sin duda de con más *sollārī, con sollus variante expresiva de solus, gr. $\delta \lambda \circ$. La $\bar{o}$ por alargamiento compensatorio de la vocal anterior, al simplificarse la $l l$ (cf. EMERITA 38,1970 , p. 207 ss.).

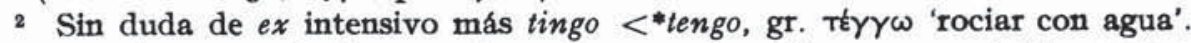
La $u$, pasada por analogía a re-stinguo < re-más extinguo, y probablemente a in-stinguo < in-más stingo, gr. $\sigma \tau i \zeta \omega$, y a veces incluso a tinguo $=$ tingo, debió penetrar en el grupo a través de ex-tinguo, para diferenciarle de los compuestos con tango (at-tingo, con-tingo, per-tingo), y bajo el influjo analógico de unguo, unxi, unctus: ex-tinguo, extinxi, extinctus. Como debió extenderse luego a distinguo, instinguo, tinguo bajo el influjo de la misma analogia distinxi, -nctus, instinxi, -nctus, tinxi, tinctus.

Es decir, que el hecho principal que más ha despistado a los autores modernos, la $u$ anorgánica de estas formas, tiene un origen claro. $\mathrm{Y}$ la otra causa de las perturbaciones, la $s$ anorgánica de ex-s-tinguo tiene también una causa completamente natural. Es que en la lengua popular la $x$, sobre todo la apoyada, se pronunciaba como $s$. L,o cual produjo muchas veces las grafías $s x, x s, x x$, como hipercaracteríación y para subrayar la pronunciación de $x$ en vez de $s$. La importancia que hechos como este tuvieron en la fonética latina puede verse en $* \mathrm{E} 1$ significado de la pronunciación popular en el conjunto de la fonética latina", en Actas del 5." Congreso Español de Fstudios Clásiios, p. 52 ss. Ahora bien, con el tema tinguo precedido de $s$ hubo en latín, aparte de ex-tinguo, otros verbos di-stinguo e instinguo. No tiene, pues, nada de extraño que por influjo de éstos (di-stinxi e intinxi) se llevase la $s$ a $e x-s$-tinxi, algo así como a la inversa se llevó la $u$ de extinguo, tinguo a di-stinguo, in-stinguo. 
$\mathrm{Y}$ entre los con in-: ignoscere 'perdonar', impetrāre 'conseguir algo con esfuerzo', impingere 'hincar o meter algo con esfuerzo', incessere (de *incassere?) 'precipitarse sobre, atacar', incidere 'cortar en pequeños trozos', incitāre 'estimular, empujar con fuerza', infringere 'hacer pequeños pedazos, hace añicos', innìti 'apoyarse con fuerza', instigäre (frente a stingere) 'aguijonear', inuidère 'clavar la vista en alguno', luego 'odiar', inuestigäre 'descubrir algo como resultado de una pesquisa diligente', irrìdère 'hacer irrisión de algo', irruere 'precipitarse con fuerza sobre algo', etc.

$\mathrm{Y}$ entre los con ob-: offirmāre 'mantener con firmeza', obmanère 'esperar largo tiempo', obnīti 'resistir con energia', obsecräre 'rogar con insistencia', obseruāre 'mirar con atención', obstināre 'persistir con firmeza', obstupescere 'quedar atónito', obtuēri 'mirar con fijeza, mirar de frente', occidere 'cortar en trozos, matar', opplère 'llenar por completo', opprimere 'aplastar', optäre (de *oppetāre < oppetere) 'desear con ansia', obtundere 'golpear con fuerza o repetidas veces', etc.

El grupo que ofrece menos ejemplos de esta clase es el de los formados con prae, en el que apenas pueden citarse más que algunos aislados con valor intensivo claro, como praefulgēre 'brillar con una luz viva', praegrauāre 'hacer muy pesado', praeualēre 'ser muy fuerte'. Un hecho doblemente extraño, porque prae fue el prefijo que dio uno de los mayores grupos de compuestos intensivos después de per-. Lo que algunos de estos compuestos tienen es un sentido de superioridad, debido a que la idea de 'delante' suele llevar adherido muchas veces un matiz de superioridad. Así 'el primero' en muchas escalas de valores equivale en muchas lenguas a un superlativo 'el mejor'. Y de ahí que en latín mismo el superlativo optumus se formó sobre el adverbio ob 'delante' (cf. EMERITA 42, I974, p. III ss.). Y de ahí que primus, priōres y optimàtes en el orden político significasen en latín 'los mejores o los nobles'. Y este valor destacó con fuerza especial en unos cuantos verbos, algunos de uso muy corriente, como praecellere, praeesse, praeèminēre, praeferre, praeponere, praesidēre, praestäre, praeualēre. $\mathrm{E}$ incluso se dio fuera de la composición en expresiones de sentido comparativo, como prae ceteris, prae illis, prae omnibus, frecuentes sobre todo a partir de los autores arcaizantes (Gelio, Frontón, Apuleyo), pero inspirados sin duda en otros similares del latín arcaico, como P1., Mil. II 40: Non sum dignus prae te. Parece algo anómalo que acercándose tanto el valor intensivo este prae tardase tanto en afirmarse como prefijo intensivo. Pero esto pudiera deberse al predominio que en esta función tuvo el per- en el ide., y al menor desarrollo del prae en aquella época más antigua. Fue sólo al final del desarrollo cuando se perdió la conciencia 
de la relación entre el valor del per y el sentido intensivo, cuando el prae tendió en parte a sustituirle.

En todo caso se comprende que ese valor intensivo tuvo que pasar a los participios y formas nominales de los verbos. No tiene, pues, nada de extraño que por analogía de éstas, y lo mismo qúe ocurrió en el per, la formación se extendiese a formas nominales, aunque no se apoyasen en un verbo compuesto. Lo que se nota muy claro es que los compuestos de este tipo con las otras preposiciones no tuvieron ni de lejos la fuerza expansiva que los compuestos con per-. Y otra cosa que se advierte es que en los con per, y en parte en los con prae son muchos más raros los casos de la debilitación semántica que en los demás compuestos fueron, cosa general. Pero esto hay que atribuirlo a que fueron los con per el terreno en el que el procedimiento se apoyó en una tradición más antigua y fuerte. Más detalles sobre esto pueden verse infra.

$\mathrm{Y}$ dentro de este contexto hay que enjuiciar a su vez los compuestos de sentido atenuado con sub-, como subagrestis, subaquilus, subiratus, subniger, etc. Ya que también en éstos la esencia del fenómeno consistió en que el sentido de suyo local de $s u b$ - se convirtió en un matiz de la intensidad; en un matiz atenuado (o poco acentuado), pero en el fondo de naturaleza igual al intensivo, que adquirieron en composición otras preposiciones $^{1}$. Y la prueba de esa identidad de naturaleza entre el valor intensivo y el atenuado es que en los compuestos distintos del per- y prae- alternan indistintamente los dos valores.

Por lo demás es claro, dada la identidad de sus elementos constitutivos y de sus sentidos, que las formas latinas no pueden separarse

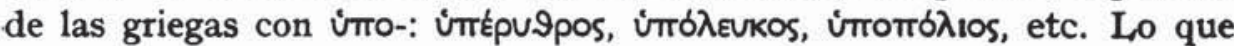
resulta mucho más difícil de aceptar es la explicación que de esta relación suele darse. Una explicación sugerida sobre todo por el hecho de que las formas griegas no aparecen hasta Anacreonte (siglos VI-v) con

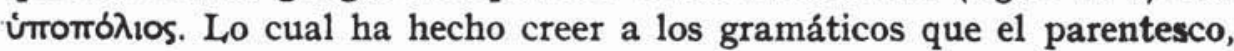
al parecer indiscutible entre ambas clases de formas, no pudo remontar al ide., y que por lo tanto las formas latinas tuvieron que ser un calco lingüistico de las griegas. Hipótesis que se ha creído avalada por el hecho de que el terreno, donde en ambas lenguas arraigó la formación, fueron los adjetivos de color.

Así Debrunner, Griech. Wortb., p. 27; Sommer, Ahhijavāfrage und

1 Cf. Donato, quien a propósito del subtristis de Ter., Andr., p. 447 comenta: «subs temperamentum est plenae pronuntiationis, ut subridet non ad plenum ridet. 
Sprachwissenschaft, Münchener Akad. Abh., Heft 9, I934, e $I F$ 55, 1937, p. I69; Kretschmer, Glotta 21, 1932, p. 213 y 24, 1935, p. 203; Schwyzer, I, p. 436; Frisk, Etym. Wb., etc. Hipótesis a la que se han adherido gran parte de los latinistas que en general no han reconocido más compuestos intensivos que los con per- y prae-.

Aunque la actitud de los latinistas ante el problema revela una gran inseguridad. Por ejemplo, Stolz-Leumann, $H$. Gr.6, p. 40r, afirma categóricamente que el tipo latino con $s u b$ - fue una traducción o calco del tipo griego con úmo-, y que se introdujo en primer lugar en los adjetivos de color: subaquilus, subniger, subrufus, etc. En cambio WaldeHofmann, $W b_{.3}$, s. u. $s u b$, se limita a indicar que las formas latinas pudieron ser calco de las griegas con úrro- pero sólo 'en parte'. Expresión imprecisa y vaga, puesto que Hofmann incluye entre los compuestos con $s u b$ - formas morfológica y semánticamente de tipo muy distinto: compuestos de origen verbal al lado de otros claramente nominales, y dentro de estos compuestos hipostáticos. al lado de otros en el que el $s u b$ - tuvo función de adverbio y otros de sentido intensivo atenuado. De modo que no es fácil adivinar a qué formas consideró él calcos del griego. Aunque mi impresión, como veremos, es que, fuera de en algunos casos de compuestos atenuados de época tardía, el griego influyó muy poco en la formación latina. Por su parte frente a estos ErnoutMeillet, $D E L L$ (al que se adhirió André, loc. cit.) cree que los compuestos latinos pudieron ser formaciones latinas independientes de las griegas; formaciones en concreto creadas por analogía, y como contrapartida de los compuestos de sentido opuesto con per- y super-. Pero tampocc esta teoria ha conseguido adhesiones firmes. Y de ahí las vacilaciones que se notan en los autores más recientes. Por ejemplo, en Bader, quien aunque inclinándose por la hipótesis del calco griego (op. cit., p. 359) tampoco rechaza la posibilidad de la hipótesis de ErnoutMeillet Y, por ejemplo, en M. Díaz y Díaz, Los adjetivos latinos compuestos con sub-, EMERITA 32, 1964, pp. 67-ror, quien coincidiendo en parte con Walde-Hofmann, sostiene que la formación debió tener raf́ces típicamente latinas (p. ror), pero que luego se desarrolló bajo una cierta tutela griega; y por otra parte afirma que las dos teorías más'bien que opuestas deben considerarse complementarias. Aunque, como Hofmann, tampoco precisa de manera exacta los límites de cada una de estas dos clases de formas.

Ahora bien, a mí no me cabe duda que la hipótesis de EirnoutMeillet carece de fundamento, puesto que no hay correspondencia, ni siquiera de oposición, entre los sentidos de per 'a través de' y de $s u b$ 'dẹbajo'. Entre los que existe sin duda una oposición es entre los com- 
puestos con $s u b$ - y los con $s u p e r$ - de la época tardía del latín cristiano ${ }^{1}$. Pero éstas fueron claras formaciones artificiosas. Formaciones artificiosas, puesto que no aparecen más que en traducciones del griego, y de las que no quedó la menor huella en las lenguas romances. Ya que ejemplos aislados como superdifficile o superfine, etc., son evidentemente claros cultismos. Lo que demuestra que nunca llegaron a penetrar en la corriente general de la lengua. Frente a los con $s u b$-, ricamente atestiguados ya en Plauto y normales en todas las épocas, y que han sobrevivido con plena vitalidad, como veremos, en una parte de la Romania. Es pues, imposible concebir que ni los compuestos con per-, ni menos aún los con super, hubiesen podido contribuir, ni a la formación ni al desarrollo de los compuestos con sub-. Aparte de que esa teoría obligaría a romper la relación indiscutible entre las formas latinas con $s u b$ - y las griegas con úmó-. Pero no es menos cierto que la hipótesis del calco tropieza a su vez con dificultades insalvables. Pues los calcos lingüísticos, en latín como en cualquier lengua, suelen servir para introducir ideas que la lengua receptora no poseía; en particular ideas técnicas. Así, por ejemplo, vemos que gran parte del léxico latino de la Gramática, la Retórica, la Filosofía y las ciencias en general se formó mediante la traducción de términos del griego, que fue donde las ciencias se constituyeron. Lo cual suele llevar consigo que los calcos apenas pasen las fronteras de las lenguas técnicas. Mientras que los compuestos con $s u b$ - no introducen en latín ninguna idea nueva, sino que sirven sólo para añadir un matiz nuevo a ideas de uso general. Es decir, que más que un calco léxico serían un calco morfológico. Fenómeno este en teoría posible, pero mucho más raro que el calco léxico. $\mathrm{Y}$ en muestro caso doblemente inverosímil, puesto que el latín poseía recursos morfológicos para cubrir esa función. Por ejemplo la expresión perifrástica con adverbios como paulō, parum, aliquantō tristis, o dūrus, o dulcis', etc.; o el uso de sufijos diminutivos como subargutulus, subcrassulus, subturpicuhis, bellus, blandulus, misellus, nouellus, primulus, tenellus, pulchellus, etc.; o los comparativos sin segundo término de comparación: agrestior, obscūrior, dürior, uetustior, etc. Aunque, por cierto, buena parte de los compuestos con $s u b$ - se dan en adjetivos que por diversas circunstancias no tuvieron comparativos sintéticos: albus, albidus, aquilus, aurātus, argenteus, crispus, lüridus, niger, rufus, rusticus, etc. Que fue la causa del arraigo especial que la formación alcanzó en los adjetivos de colores.

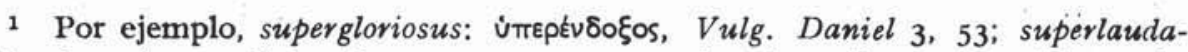
bilis: ن்tтepalvetos, Vulg. Dan. 3, 53 у 54; superabnegatiuus: ن் Boec., Cic. top. 5, Ir 34 A. 
De cualquier forma, y por encima de todo, el hecho es que las formas de valor atenuado con $s u b$ - gozaron sin duda de gran favor en la lengua popular. Esto hay que deducirlo de una serie de circunstancias. Por ejemplo, en primer lugar del hecho de que la formación está atestiguada ya en P1. con no menos de once ejemplos, el grupo más numeroso en él de compuestos intensivo-atenuados después de los con per-. Hecho, como se ve, difícil de compaginar con la idea del calco griego. $\mathrm{Y}$ en segundo lugar del hecho de que a la inversa en la alta poesía la formación no está representada más que por un solo ejemplo, sublustris. Lo cual constituye la prueba más definitiva contra la hipótesis del calco. Ya que precisamente el helenismo en los diversos planos de la lengua fue un rasgo típico y esencial del lenguaje poético. $\mathrm{Y}$ naturalmente no se concibe que una lengua penetrada de helenismos en todas las direcciones hubiese opuesto esa resistencia invencible frente a un procedimiento importado del griego. $\mathrm{Y}$ en fin de la vitalidad que el procedimiento conservó en la lengua de los padres de la Iglesia y de los autores eclesiásticos de los últimos siglos del imperio.

Un hecho este que por cierto no parece que Díaz y Díaz haya apreciado del todo exactamente. Pues él, fundándose en que los P. P. de la Iglesia y los escritores cristianos más cultos estuvieron fuertemente influidos por la lengua de los clásicos (cosa de que no puede dudarse), y aceptando la opinión corriente de que a los dialectos romances apenas pasaron más que uno o dos compuestos con $s u b$-, por lo demás con un ámbito de extensión muy limitada, deduce en su artículo que la forma tuvo un carácter eminentemente literario. Pero lo cierto es que en la lengua de los padres de la Iglesia, calcada en lo esencial en la de los clásicos, penetraron una multitud de elementos populares, motivados en parte por el deseo de hacerla más accesible al nivel cultural de las capas a que iba dirigida. $Y$ por otra parte es claro, aunque ni los romanistas ni los latinistas lo hayan advertido, que el sub- ha conservado su capacidad de dar compuestos atenuados hasta nuestros días, en una zona amplia de la Romania. Por ejemplo, en concreto en español, donde existen actualmente formas de uso corriente en la lengua popular con un elemento prefijal so-, sin duda continuación del lat. $s u b$; a saber, las formas insultantes del tipo de so-bobo, so-tonto, so-burro, so-animal, etcétera. Lo cual demuestra que a finales del imperio fue éste el prefijo que poseyó vitalidad más pujante en la lengua popular; más pujante que el mismo per-, como notó ya certeramente Woelfflin, Philologus 34 , I876, p. r65. Y por lo tanto obliga a suponer que los compuestos con $s u b$ - de los P. P. de la Iglesia, más que a la tradición clásica tuvieron que deberse a un influjo de la lengua popular. $Y$ en definitiva constituye 
la prueba más significativa del carácter popular de la formación. Carácter naturalmente inconciliable con la hipótesis de su origen griego. Hay, pues, que admitir frente a la opinión más extendida que los compuestos con $s u b$ - no pudieron ser calcos griegos, sino que tuvieron que surgir espontáneamente en latín. Espontáneamente, pero sin duda a través de un proceso parecido al que produjo que el úmó, de suyo adverbio de sentido local, se convirtiese en exponente de la atenuación ${ }^{1}$.

¿Que cómo podría haberse llegado en ambas lenguas a este resultado? Pero la pregunta en lo que se refiere al latín parece que, después de lo dicho sobre otras preposiciones, tiene una contestación obvia. Pues, como hemos indicado, los matices de la atenuación y de la intensidad no son dos nociones por naturaleza opuestas o distintas, sino formas y grados de un fenómeno en el fondo único. Es decir, que los compuestos claramente intensivos y los atenuados pueden considerarse modalidades de una misma categoría gramatical. Por lo demás era natural que un sentido como el de 'abajo, debajo, desde abajo' junto a ideas verbales tendiese a rebajar o a atenuar el sentido del compuesto. $\mathrm{Y}$ efectivamente se ve que compuestos verbales de este tipo existieron ya en latín arcaico, y no dejaron de producirse en época posterior. Por ejemplo, subblandiri 'halagar', subolère 'sentir un ligero olor, darle a une un tufillo de algo'; succingere (de donde succinctus) 'vestir ligeramente', succensēre 'enojarse un poco', suspicäri 'ver debajo, entrever, sospechar' (Plauto), subrīiēre 'sonreir' (Varrón), subaccūsāre 'acusar ligeramente', subdubitäre 'tener alguna duda', subinuidēre 'tener alguna envidia', subirasci 'enojarse un poco' (Cicerón), subolfacere 'ventear, olfatear' (Petronio), subbidere 'beber un poco' (Suetonio), etc. Se comprende, pues, que a partir de éstos se formasen compuestos intensivo-atenuados nominales, idénticos por naturaleza a los compuestos intensivos que se formaron con per-, prae- y otras preposiciones. El que lo mismo en griego que en latín estos compuestos alcanzasen una extensión especial en ciertas categorias como los adjetivos de color, hay que atribuirlo no a un influjo del griego sobre el latín, sino sencillamente a que los adjetivos de color en general no admitieron formas comparativas o elativas.

El problema que estas construcciones plantean es que la explicación de los hechos latinos no puede separarse de la de los correspondientes

1 Lo cual no excluye que algunos compuestos de época tardia que aparecen sólo en obras técnicas o en traducciones del gr. (por ejemplo en Oribasio, Dios. córides, Celso, etc.) penetrasen en latín directamente del griego, como indica Diaz. 
griegos, y que a éstos hoy suele considerárselos salidos de expresiones como ímó $\tau_{1}$ mó $\lambda$ ıos (así por lo menos Schwyzer, loc. cit., de acuerdo con Sommer, Ahhiyavafrage und Sprachw). Pero lo cierto es que tal hipótesis tiene una base sumamente dudosa y problemática. Ya que en primer lugar se apoya en unos testimonios aislados y relativamente tardíos, por lo menos posteriores a la aparición de los compuestos con úmo-.

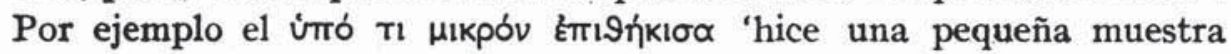

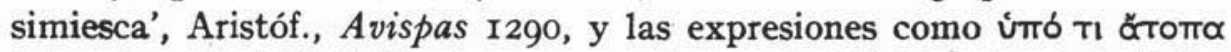

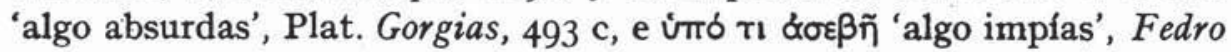
242 d. Expresiones que desde luego corresponden al sentido de los com-

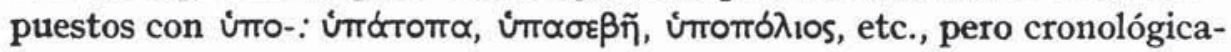
mente posteriores a éstos y limitadas al ático. $\mathrm{Y}$ que por lo tanto parece completamente inverosímil que pudiesen haber sido el punto de partida de los compuestos. Y aun más difíciles de justificar y concebir son los cambios que habría que supoper en el paso de ímó $\tau_{1} \pi \dot{b} \lambda_{10 S}$ a ímotró $\lambda_{10}$. Es decir, la elipsis del $\tau$ y el trastrueque de la relación sintáctica del ưró, que habría pasado a determinar en vez de al pronombre indefinido al adjetivo.

No sólo esto, sino que compuestos idénticos por la forma y el sentido a los griegos con úrro- se dieron también, además de en latín, en ai. con $u p a-y$ en celta con fo-: fo-dord 'murmullo' < dord 'griterío'. Lenguas en las que no se puede suponer un influjo griego ni latino, y que por lo tanto tuvieron que llegar a sus compuestos de manera independiente. De manera independiente, pero sin duda por un camino parecido, y bajo la presión de fuerzas iguales a las que produjeron las formas griegas. Y la cosa es que en ninguna de esas lenguas existen construcciones como las que según Sommer dieron origen a los compuestos griegos. Luego, evidentemente, hay que concluir que la hipótesis de Sommer, aunque aceptada al parecer por la totalidad de los autores, es falsa; es decir, que los compuestos con ímo- no pudieron en absoluto salir de

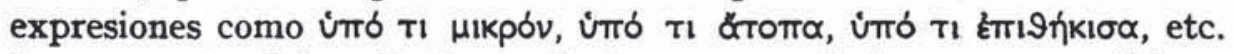
Lo que no tendría nada de particular es que a la inversa estas últimas expresiones hubiesen surgido sobre los compuestos con ímo-, y como un desarrollo de la idea de "algo» implícita en ellos. Ya que evidentemente, aunque en griego no estén atestiguados hasta Anacreonte, tales compuestos procedieron del ide. Sobre esto no cabe la menor duda, dado que están atestiguados en las cuatro lenguas citadas. Mientras que

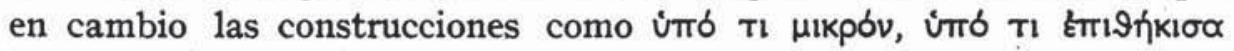
sólo se dan en griego y en fecha relativamente tardía.

Por cierto que esto lo vio ya Kretschmer, Glotta 24, I935, p. 203 ss., a pesar de que él creyó, con la mayoría de los autores, que el tipo latino 
subrufus, subrusticus, etc. fue un préstamo del griego, sin darse cuenta de los múltiples argumentos que hacen imposible tal teoría. Pero en todo caso Kretschmer notó bien que donde se produjo de manera natural la conversión en atenuante del sentido local del úmo- fue en los compuestos verbales. De donde dedujo que fue en ellos donde se originó el fenómeno, traspasado luego a los compuestos nominales. Hipótesis que concuerda plenamente con lo que se deduce del estudio de los hechos latinos análogos. Lo que pasa es que esa hipótesis no han querido admitirla la mayoría de los autores, porque se ha crefdo que los compuestos vierbales con el sentido atenuado de 'un poco' todavía no existieron en la época de Homero. Pero tal objeción carece ya en principio de fuerza, porque tampoco los compuestos nominales con úroaparecen hasta mucho después de Homero. Y por lo demás hay razones para pensar que ya en época de Homero el ưró había adquirido en

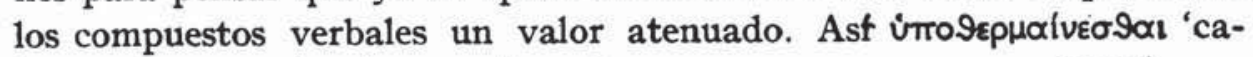
lentarse un poco' e írtoтrepkঝ́zєıv 'ennegrecerse un poco, madurar'.

$\mathrm{Y}$ desde luego se ve que en época posterior tales formaciones, lo mismo que las latinas con $s u b$-, fueron haciéndose más o menos frecuentes,

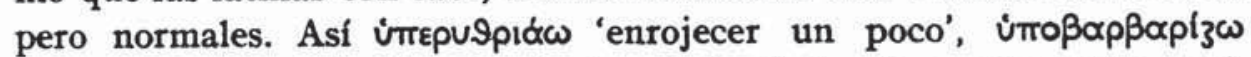
'tener una pronunciación algo bárbara', ن்roßpéX $\omega$ 'humedecer un poco', ن

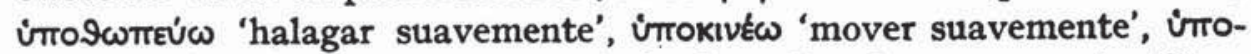
$\kappa v i z \omega$ 'picar o excitar suavemente', ن்

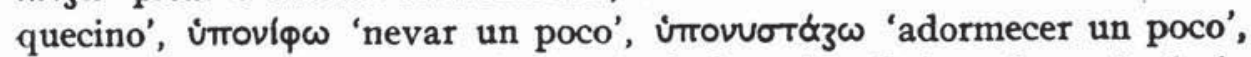

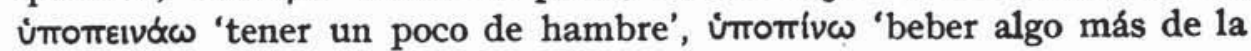
cuenta, achisparse', i்motrv£ $\omega$ 'soplar un poco', etc. Ahora bien ya hemos visto que en latín los compuestos nominales, todos con prefijo intensivo (entre ellos los con sub-), admiten una explicación completamente natural a partir de los compuestos verbales del mismo tipo. $Y$ por otra parte ya he dicho también que lógicamente es imposible separar las formas con irro- de las latinas con $s u b$. Luego todo indica que efectivamente los compuestos con ن́mó, lo mismo que los latinos con $s u b-$, y que seguramente los del ai. con $u p a-$, y los del celta con fo-, no fueron más que extensiones a temas adjetivos de un tipo surgido en los temas verbales $^{1}$. Lo cual no quiere decir, según veremos luego, que el proceso

\footnotetext{
1 De un tipo que posteriormente, a partir de los temas adjetivos, se habria

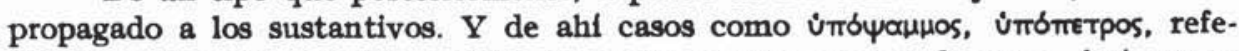
ridos por Herodoto a Libia y Siria, respectivamente, y como útroouos, úmótpuyos, úmómtrpos. Casos que suelen explicarse como "exocéntricos", pero que a mi juicio

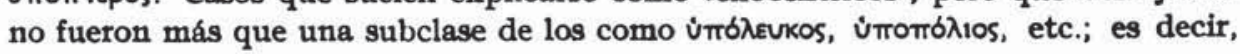


de la composición (es decir, la fusión en una unidad cerrada de los elementos componentes) se hubiese realizado ya en ide., ni en los compuestos verbales ni en los nominales, ni en los compuestos con imó: sub- ni en los con las otras preposiciones. $\mathrm{Y}$ el que en concreto la formación con úrro- no aparezca documentada en Homero, ni en la antigua poesía épica, pudo deberse a la misma causa que impidió el que los compuestos latinos con $s u b$ - no se aclimatasen en la lengua poética; es decir, a su carácter eminentemente popular y familiar.

\section{(Continuará)}

ANgel, Pariente

una manifestación partitular de un fenómeno que en los compuestos con prefijo intensivo tuvo una extensión general; a saber el traspaso a los temas sustantivos de una construcción en principio propia de los temas adjetivos. De modo que lo esencial en tales formas fue su sentido atenuado: 'algo arenosa', 'algo pedregosa', 'algo con un olorcillo agradable', 'algo feculento'. Un sentido que a veces como en úmótrtepos 'alado' incluso terminó desvaneciéndose. Algo así como también en Evsepuos 'caliente', etc., el êv- no tuvo más valor que el de un prefijo 'expletivo'. Y la prueba de que fue ese, y no el local, el sentido más exacto del úrro- es que Hdt. para calificar a Libia se valió, no de úrół

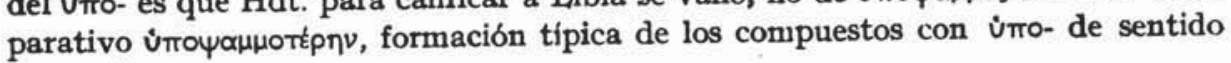
atenuado. 